Masthead Logo

Wayne State University

Law Faculty Research Publications

Law School

$2-1-1990$

\title{
Bull Durham and the Uses of Theory
}

Steven L. Winter

Wayne State University

\section{Recommended Citation}

Steven L. Winter, Bull Durham and the Uses of Theory, 42 Stan. L. Rev. 639, 694 (1990)

Available at: https://digitalcommons.wayne.edu/lawfrp/377

This Article is brought to you for free and open access by the Law School at DigitalCommons@WayneState. It has been accepted for inclusion in Law Faculty Research Publications by an authorized administrator of DigitalCommons@WayneState. 


\title{
Bull Durham and the Uses of Theory
}

\author{
Steven L. Winter*
}

This essay examines the trio of antifoundationalist claims developed by Stanley Fish: that practice is impervious to theory; that theory has no consequences for change; and that critical self-consciousness is neither possible nor necessary. The essay argues that Fish's claims rest on vestigial objectivist assumptions which have been undermined by recent developments in cognitive theory. It offers instead a nonobjectivist account of change that recognizes the role of human imagination in the ongoing process of social construction. This account suggests that current legal theory is in the kind of crisis state that typically presages a paradigm shift. The essay concludes with an examination of "situated self-consciousness" and the practices of lawyering and judging. It argues that self-consciousness is necessary if we are to avoid blind acceptance of the status quo and acknowledge moral responsibility for the consequences of power.

I. "Always and Already" Stanley Fish............... 640

II. Dissecting the Durham Bull.................... 644

A. "Look, Ma, No Consequences!" ................ 645

B. The Worm at the Heart of Being Fish ............... 649

C. Don't Think Twice, It's Alright ................ 657

III. Theory, Change, and the Role of Imagination ........ 664

A. Accidents Will Happen .................... 665

B. Changes ................................ 670

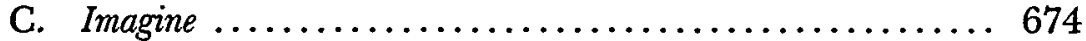

D. Moods for Moderns ....................... 677

IV. Situated Self-Consciousness ................. 681

V. Everything Matters, Always ................ 691

* 1990 by Steven L. Winter. Associate Professor, University of Miami School of Law; B.A., Yeshiva College, 1974; J.D., Columbia University, 1977. As always, I am grateful to and dependent upon many friends who have helped with insights, suggestions, provocative questions, and comments on the draft. Many thanks, therefore, to Tony Amsterdam, George Lakoff, Bruce Ackerman, Jan Deutsch, Mark Johnson, Pierre Schlag, Jeremy Paul, David Caploe, Fred Schauer, Jennifer Jaff, Mark Tushnet, Mark Turner, David Carlson, Milner Ball, Pat Gudridge, Mary Coombs, Minnette Massey, Marc Fajer, Robert Williams, Jim Kainen, and Lynn Winter. I am also grateful to Stanley Fish, who graciously commented on the draft at a faculty seminar at the University of Miami School of Law.

This article is dedicated to Tony, George, Bruce, Jan, Mark, and Pierre: for sharing with me the pleasures of dialogue and the gift of friendship, which mean much more than they know. 
Here's a little song I wrote,

You might want to sing it note for note,

Don't worry, be happy.

In every life we have some trouble

But when you worry, you make it double.

Don't worry, be happy

Don't worry, be happy now ... ${ }^{1}$

\section{I. "Always and Already" Stanley Fish}

Imagine that you are Stanley Fish. You are Arts and Sciences Distinguished Professor of English and Law at Duke University in Durham, North Carolina. You are very, very smart. So smart, in fact, that you run antifoundationalist rings around people as distinguished as Ronald Dworkin, ${ }^{2}$ Owen Fiss, ${ }^{3}$ and Roberto Unger ${ }^{4}$ and as diverse as Mark Kel$\operatorname{man}^{5}$ and Michael Moore. ${ }^{6}$ You are forever reinforcing "the lesson that we are always and already interpretively situated"7 by demonstrating the lurking objectivist assumptions behind their disparate positions. This is a simple matter for you, (dare we say it?) like shooting fish in a barrel.

So, imagine that you are Stanley Fish. You love baseball and Baltimore. Accordingly, you are only doing what comes naturally when you use an anecdote about former Baltimore Oriole pitcher Dennis Martinez to illustrate your claim that theory (properly defined) is irrelevant to practice. A reporter from the New York Times asked Martinez what "words of wisdom" Orioles manager Earl Weaver had "imparted" to him before the game. Martinez responded: "He said, 'Throw strikes and keep 'em off the bases,' . ... and I said, 'O.K.' "8 You tout the 1988).

1. Bobby McFerrin, Don't Womy, Be Happy, recorded on Simple Pleasures (EMI Manhattan

2. See, e.g., Stanley Fish, Still Wrong After All These Years, 6 LAw \& PHiL. 401 (1987), reprinted in Stanley Fish, Doing What Comes Naturally: Change, Rhetoric, and the PracTice of Theory in Literary and Legal Studies 356 (1989) [hereinafter Doing What Comes NATURALLy]; Stanley Fish, Working on the Chain Gang: Interpretation in Law and Literature, 60 TEx. L. Rev. 551 (1982), reprinted in Doing What Comes Naturally, supra, at 87; Stanley Fish, Wrong Again, 62 TeX. L. Rev. 299 (1983), reprinted in DoIng What Comes NatuRally, supra, at 103.

For a related critique of Dworkin's serial novel analogy for judicial decisionmaking, see Steven L. Winter, The Cognitive Dimension of the Agon Between Legal Power and Narrative Meaning, 87 MrCH. L. Rev. 2225, 2260-61 (1989). In that essay, I employ the perspective of cognitive theory to incorporate what is valuable in Fish's critique but avoid its totalizing assumptions.

3. See, e.g., Stanley Fish, Fish v. Fïss, 36 Stan. L. Rev. 1325 (1984), reprinted in Doing What Comes Naturally, supra note 2, at 120.

4. See, e.g., Stanley Fish, Dennis Martinez and the Uses of Theory, 96 YaLE L.J. 1773, 1780-81, 1799-1800 (1987), reprinted in Doing What Comes Naturally, supra note 2, at 372, 379-80, 397-98 [essay hereinafter referred to as Dennis Martinez]; Stanley Fish, Unger and Milion, 1988 Duke L.J. 975, reprinted in Doing What Comes Naturally, supra note 2, at 399.

5. Dennis Martinez, in Doing What Comes Naturally, supra note 2, at 392-98.

6. Id. at 379-84, 397-98.

7. Critical Self-Consciousness, or Can We Know What We're Doing?, in Dorng What Comes Naturally, supra note 2, at 436, 437 [hereinafter Critical Self-Consciousness].

8. Dennis Martinez, in Doing What Comes Naturally, supra note 2, at 372. 
brilliance of this "account of what transpires between fully situated members of a community."9 You admire Martinez's philosophical acumen and gleefully applaud the way he "drives the lesson home with a precision that Wittgenstein might envy: 'What else could I say? What else could he say?" "10

This is all such good fun because the anecdote dovetails nicely with the point you made with such verve in Fish v. Fiss ${ }^{11}$ : Even though a simple reading of the Federal Rules of Civil Procedure, for example, would tell one very little, the rules are nevertheless understandable because every person engaged in a practice like lawyering is "already embedded in the context of assumptions and practices that make it [the rule] intelligible, a context that at once gives rise to it (in the sense that it is a response to needs that can be felt) and is governed by it." 12 So you commend Weaver for declining to "impart" more than the situated knowledge Martinez already possesses. "[I]t would have been totally inappropriate for him to have done so." 13 For you understand what has escaped Dworkin, Fiss, Unger, and so many other theorists: that "there are two distinct activities-playing baseball and explaining playing baseball [or practicing law and theorizing about law] -and that ... there is no relationship between them whatsoever." 14

Now imagine that you are Stanley Fish watching the movie Bull Durham. ${ }^{15}$ The movie is especially fun because it is about your local minor league baseball team, the Durham Bulls. Ebby Calvin "Nuke" LaLoosh, the talented but undisciplined rookie pitcher (played by Tim Robbins), is being groomed for the major leagues. Crash Davis, the veteran minor league catcher (played by Kevin Costner), has been brought on to smooth Nuke's very rough edges. You nod approvingly when Crash and Nuke first meet. "I'm Crash Davis. I'm your new catcher and you just got lesson number one: Don't think; it can only hurt the ball club."

You are really enjoying the film up until the point when Crash's tutelage begins to bear fruit. Nuke has been pitching like an ace; the team has rallied and is tied for first. The snag comes when the team goes on the road. On the bus, Nuke is climbing all over the seat-backs in childlike exuberance. He drops into the seat next to Crash. "Teach me something new, man. I need to learn. Teach me something."

"Well, you got something to write with? Good, it's time to work on your interviews .... You're gonna have to learn your cliches ....

\footnotetext{
9. Id.

10. Id.

11. Fish v. Fiss, in Doing What Comes Naturaliy, supra note 2, at 120.

12. Id. at 123.

13. Dennis Martinez, in Doing What Comes Naturally, supra note 2, at 373.

14. Id. at 374 . To be accurate, Fish qualifies this totalizing statement with the caveat that he means this only "in a strict sense" which he explains later. Id. I discuss the validity of Fish's "strict sense" in notes 61-94 infra and accompanying text.

15. (Orion Pictures 1988) (written and directed by Ron Shelton).
} 
Write this down." Crash rehearses some omnibus lines, lines to fit almost any sports writer's question, lines like "We got to play them one day at a time" and "I'm just happy to be here; hope I can help the ball club." By the end of the movie, Nuke has been called up to the majors. You watch with a sinking feeling as he is being interviewed. He intones the lines knowingly, as naturally and spontaneously as if he had been doing television interviews all his life. "A good friend of mine used to say: 'This is a very simple game. You throw the ball; you catch the ball; you hit the ball. Sometimes you win. Sometimes, you lose. Sometimes, it rains.' Think about that for a while."

Now this is good stuff for the average movie viewer; this last scene elicits a knowing laugh from most of us. But you are not the average moviegoer; you are Stanley Fish. You have already committed yourself in print to the proposition that between fully situated members of a community, there is nothing else to say. You experience a momentary terror. You have taken Martinez's comment as a true report of what baseball players actually say to each other. Now, however, the simplicity and sincerity of Martinez's response has been put in question. What if the only pitch Dennis Martinez was getting across that day was just an old baseball bromide? Could you have been hoodwinked? What if "Throw strikes and keep 'em off the bases" is just another nostrum learned in the minor leagues? Did you blow it when you used it as realworld confirmation of your claims?

Worse yet, you realize that you have committed a double objectivist fallacy in repeating Martinez's quip unreflectively as if it were both "literal" and "true." "Literal" in that you took the quip to mean what it said in some straightforward and uncomplicated sense. "True" in that you took the quip as a simple "report" of "the event."16 But what if Weaver did impart some theoretical secret that Martinez did not care to share with the reporter from the Times? What if Martinez was engaged in the distinct practice of doing press interviews? What if Martinez was just being ironic? What was apparently light entertainment has now become the occasion for acute academic angst.

A lesser antifoundationalist could perhaps avoid the embarrassment. But in your rush to pass (anti)metaphysical judgment you are undone by your own antifoundationalist arguments. You have "always and already" proclaimed "that there is no such thing as literal meaning, if by literal meaning one means a meaning that is perspicuous no matter what the context and no matter what is in the speaker's or hearer's mind." 17 Rather, you have argued frequently that "[m]eaning is always a function of the interpretive condition of production and reception and never a function of formal linguistic structures." 18 In that case,

16. Dennis Martinez, in Doing What Comes Naturally, supra note 2, at 372.

17. Introduction: Going Down the Anti-Formalist Road, in DolNG What Comes Naturaliy, supra note 2, at 4 [hereinafter Anti-Formalist Road].

18. Dennis Martinez, in Dong What Comes Naturaldy, supra note 2, at $581 \mathrm{n} .2$; see also 
however, Martinez's quip cannot be taken at face value. Rather, it can be understood only in relation to the conventions of an interpretive community. 19 And it follows that anything Weaver did "impart" must remain unavailable to us because it will always be shielded behind the screen of an interpretive construction.

What to do? Are you hoist with your own petard? Not if you are Stanley Fish.

If you are Stanley Fish, you have a reserve of rhetorical and theoretical skills that you can call upon. "What is it," you think to yourself, "that really gives power to this critique?" It is the alternative version of "reality" depicted in Bull Durham. But Bull Durham is, after all, only a movie. A story. An interpretive construction of its own. "That's the ticket," you say to yourself. Your use of the story about Dennis Martinez is problematic only if the anecdote is interpreted relative to the world as constructed in the movie. Relative to some other set of interpretive conventions, however, your original account is still valid. And this proves your claim that all meaning is a function of interpretive communities and their conventions: The "meaning" of the story in the Times is something to be constructed on the basis of one's interpretive situatedness-whether inside the world of Bull Durham or inside some other set of beliefs. Even better, it also proves your anti-theory claim because that claim is one and the same as the interpretive community claim: to be a person already situated in an interpretive community is "already [to] be[] someone whose sense of himself and his possible actions is inseparable from the kind of knowledge that words of wisdom would presume to impart."20

You are pleased with this tour de force of self-justification, but you have yet to deliver the coup de grâce. It is simply this: You cannot be faulted for your unreflective use of the Martinez anecdote because, as you have previously explained, everybody is "always and already" unreflective. As an antifoundationalist, you reject any conception of Reason as an independent faculty, and instead understand "reason" as a product of historical and cultural forces. It follows that the inherited, "already-in-place interpretive constructs are a condition of consciousness." 21 In that case, however, one's interpretive commitments and other beliefs will always be transparent-in the sense of "invisible"-to consciousness. ${ }^{22}$

It follows, then, that the one thing you can't do in relation to interpre-

Shorl People Gol No Reason to Live: Reading Irony, in DoIng What Comes Naturally, supra note 2, at 185 ("Literal meaning, rather than being independent of perspective, is a product of perspective (it is the meaning that, given a perspective, will immediately emerge); it is itself an interpretation ....").

19. See Stanley Fish, Is There a Text in This Class?: The Authority of Interpretive Communities (1980).

20. Dennis Martinez, in Doing What Comes Naturaliy, supra note 2, at 373.

21. Id at 394 .

22. "This simply means . . that the context is so established, so deeply assumed, that it 
tive constructs is choose them, and it follows too that you can't be faulted either for not having chosen them or for having chosen the wrong ones; moreover, it follows that ... if you can't choose your interpretive constructs, then neither can you know them (in the sense of holding them in your hand for inspection), and if you can't know them, you can hardly be expected to take them into account. . . . ${ }^{23}$

Thus, whatever your critics might say about your reading of the Martinez anecdote, it only goes to prove your ultimate claim: theory and critical self-consciousness are impossible because all meaning is a function of one's situatedness within practice and within an interpretive community.

If you have stayed in character throughout this little fantasy, you can relax now. Closure has been achieved. Everything is "always and already" all right. This is what it means to be "always and already" Stanley Fish. Don't worry, be happy.

\section{Dissecting the Durham Bull}

The sinuous quality of Fish's method, the sheer rhetorical skill with which he builds his argument, is nowhere more on display than in Dennis Martinez. ${ }^{24}$ In his argument against the uses of "theory," Fish moves effortlessly from baseball to an anecdote about industrial research and development and thence to judging. In each field, practice is something one learns as one does, and does without regard to formulas or rules. "Theory" is and can only be what one says afterward in justification or, elsewhere, in participating in the "practice" of theory-talk.

Although I shall consider many of the particulars of the Dennis Martinez essay, what really piques my interest are the stronger claims: (1) that theory has no consequences; (2) that self-consciousness is neither possible nor useful; and (3) "that these truths are the occasion neither of cynicism nor of despair."25 (That is, "Don't worry, be happy.") I am interested in disputing these claims for two reasons. First, they don't square with my experience as a practitioner at either the trial or appellate level. Second, and more important, I don't believe that everything is "always and already" all right. Consequently, I am interested in doing the kind of "theory" (we might call it theory with a small-t) that "better enables us to harness the power of our understanding to trans-

is invisible to the observer ... ." Consequences, in Doing What Comes Naturally, supra note 2 , at $315,320-21$.

23. Dennis Marlinez, in Doing What Comes Naturally, supra note 2, at 394.

24. For an astute and playful deconstruction of Fish's rhetorical technique, see Pierre Schlag, Fish v. Zapp: The Case of the Relatively Autonomous Self, 76 GEO. L.J. 37 (1987). For a critique of Fish's Dennis Martinez essay that draws upon the worlds of both baseball and law, see Brook Thomas, Stanley Fish and the Uses of Baseball: The Return of the Natural, 2 YaLE J.L. \& Humanities - (1990) (forthcoming).

25. Dennis Martinez, in Doing What Comes Naturally, supra note 2 , at 380 . 
form the world in which we live."26 From Fish's point of view, I have already committed the gaffe of "anti-foundationalist theory hope."27 But, as we have already seen, everything is not always as it appears. ${ }^{28}$

To see what is wrong with Fish's strong claims, we will need to expand the field of inquiry to encompass Fish's broader arguments against theory and the usefulness of theory-talk. In this way, we will be able to get the guts of his method out on the table where we can see clearly what it is and what it is not. What we will find is that, despite the cogency of Fish's basic assumptions, his specific conclusions (propositions 1-3) are both unsupported and unpersuasive. To put it another way, while Fish is about two-thirds correct, the other third is the part that really matters.

\section{A. "Look, Ma, No Consequences!"}

Fish starts with some assumptions that are largely correct in my view. The central antifoundationalist claim is that all human knowledge is situated knowledge, "that human history is the context within which we know." 29 The implicit minor premise, familiar enough in all antifoundationalist and relativist arguments, is that there can never be an Archimedean point outside of some situated, historical practice or perspective. It is this historical and cultural situatedness which comprises the kernel of what is correct about the claim that meaning is a function of an "interpretive community." 30

From this insight, Fish deftly constructs his argument that theory has no consequences. His first move is to define "theory" in terms of this opposition between situated human knowledge and aperspectival "objective" knowledge. A project is "theoretical" for Fish when "what it seeks is a method, a recipe, with premeasured ingredients which ... [can be] ordered and combined according to absolutely explicit instructions ...."31 The purpose of theory is to produce results "that in no way depend on [one's] education, or point of view, or cultural situation," results that are, in short, objective. ${ }^{32}$ Theory "is an attempt to

26. Steven L. Winter, Transcendental Nonsense, Metaphoric Reasoning, and the Cognitive Stakes for Law, 137 U. PA. L. Rev. 1105,1107 (1989).

27. Dennis Martinez, in Doing What Comes Naturally, supra note 2, at 584 n.60.

28. The word "gaffe," a twentieth century neologism meaning faux pas or social blunder, is thought to be a derivative of "gaff" which is a spear or hook for taking or handling fish. The Random House Dictionary of the English Language 781 (2d ed. unabridged 1987) (from the Middle French gaffe for hook and gafar for seize).

29. Consequences, in Doing What Comes Naturally, supra note 2, at 324 .

30. Pierre Schlag argues persuasively that Fish's interpretive community construct operates as a "theoretical unmentionable": a kind of black box that can never be given content. There are two benefits that Fish accrues by keeping the concept relatively empty. First, to offer a developed account of interpretive communities would be to offer a theory, which is what Fish says can't or shouldn't be done. Second, it is precisely because it can't be put to any test that the concept of "interpretive communities" provides the kind of safe sense of closure illustrated in Part I. Schlag, supra note 24, at 42-47.

31. Consequences, in Doing What Comes Naturally, supra note 2, at 319.

32. Id. 
guide practice from a position above or outside it."33

Now this bete noire of Fish's is easily recognizable as garden-variety objectivism with all that it entails, including reliance on mathematics as the epitome of Reason and the model for theory. ${ }^{34}$ Fish rehearses several effective, if familiar arguments why theory of this sort is not attainable. First, the very contents of the meta-rule, as well as the "facts" from which it is abstracted, will themselves be already tainted products of situated human knowing. ${ }^{35}$ Second, and more telling, the terms of the meta-rule can never be self-declaring; the rule itself will be subject to interpretation. ${ }^{36}$ At this point, we have entered an infinite regress. There are no foundations. "It's turtles all the way down."37

But this is not what is most interesting about Fish's anti-theory claim. What is worth noting is that, in defining "theory" the way he does, he has stacked the deck in such a way that the game is already over. The historicist insight is that there is no way to get outside one's practice and the context that makes it meaningful. But once "theory" is determined to be something "outside" or "above" practice, it follows from the insight about situatedness that there cannot be any such thing as "theory" at all. Accordingly, the project of doing theory cannot have any consequences.

Now this is too easy for someone of Fish's talents, and he knows it. $\mathrm{He}$ is after bigger game; it is his fellow antifoundationalists whom he means to chasten. ${ }^{38}$ His particular target is the idea that antifoundationalist theory will have liberating consequences, "freeing us from the hold of unwarranted absolutes so that we may more flexibly pursue the goals of human flourishing or liberal conversation."39 But, Fish argues, this liberation is impossible. The insight that everything is so-

33. Id. (emphasis changed from original).

34. See id. at 317 ("The model for the "true' rule and, therefore, for theory is mathematics. ..."); Dennis Martinez, in Doing What Comes Naturally, supra note 2, at 378 ("I reserve [the] word [theory] for an abstract or algorithmic formulation that guides or governs practice from a position outside any particular conception of practice."). For a description of the basic parameters of the objectivist view and some of its problems, see Winter, supra note 26 , at 1107-10, 1118-19.

35. Consequences, in Doing What Comes Naturally, supra note 2, at 320-21.

36. Fish v. Fiss, in Doing What Comes Naturally, supra note 2, at 121.

37. See Pierre Schlag, Cannibal Moves: An Essay on the Metamorphoses of the Legal Distinction, 40 Stan. L. Rev. 929, 937-38 (1988); Roger Crampton, Demystifying Legal Scholarship, 75 Geo. L.J. 1, 1-2 (1986); Joseph William Singer, Radical Moderation, 1985 AM. B. Found. RES. J. 329, 329-30; Mark V. Tushnet, Following the Rules Laid Down: A Critique of Interpretivism and Neutral Principles, 96 HARv. L. REv. 781, 792-93 n.32 (1983). Crampton traces the turtle story to William James, who referred to rocks rather than turtles in his version. See Crampton, supra, at 2 n.4; William James, The Will to Believe and Other Essays in Popular Philosophy 104 (1897); see also Clifford GeERTZ, The Interpretation of Cultures 28-29 (1973) (turtles).

38. See, e.g., Critical Self-Consciousness, in Doing What Comes Naturally, supra note 2, at 436 ("It is now almost obligatory to genuflect in the direction of these [antifoundationalist arguments], and yet more often than not those who perform these genuflections almost immediately betray the larger insight from which they derive.").

39. Consequences, in Dorng What Comes Naturaldy, supra note 2, at 323. 
cially constructed cannot open a way to a better, more free, or unconstructed context. For, if the antifoundationalist insight is correct, there is no place to go but to some other historically situated, socially constructed context. ${ }^{40}$ Critique, no matter how rigotously deconstructive, "delivers us from the grip of one system only to deposit us in the (equally frozen) grip of another."41 Antifoundationalist theory hope is therefore doomed to failure. ${ }^{42}$ Once again, no consequences.

At this point in his demonstration, Fish pauses to respond to two counterarguments. The first is premised on the observation, noted above, that Fish has already loaded the dice in his uncompromising definition of "theory." He therefore considers a more modest notion of "theory" that would eschew the universalizing tendency of objectivist theory and content itself with producing useful empirical generalizations. Why isn't this "theory"? Fish acknowledges that we could call this theory, "but the effect of such a liberal definition would be to blur the distinction between theory and everything that is not theory." $43 \mathrm{He}$ concedes that powerful abstract generalizations or paradigms ${ }^{44}$ often function as models for subsequent work in the field. But he characterizes such efforts as "instances not of following a theory but of extending a practice .... If we like, we can always call such imitations of a powerful practice 'theory,' but ... we will have lost any sense that the-

40. Critical Self-Consciousness, in Doing What Comes Naturally, supra note 2, at 455 ("the insight of historicity-of the fashioned or constructed nature of all forms of thought and organization-is too powerful a weapon for those who appropriate it to attack the projects of others; for it turns against them when they attempt to place their own project on a footing that is different ") (emphasis in original).

41. Id. at 457 (characterizing and approving a claim he attributes to Adorno).

42. See, e.g., Consequences, in Doing What Comes Naturally, supra note 2, at 322-24.

43. Id. at 325 .

44. The term "paradigm" comes from the work of Thomas Kuhn in the history of science and refers to an "accepted model or pattern" that provides a framework for "further articulation and specification under new or more stringent conditions." THOMAS S. KuHN, The Structure of Scientific Revolutions 23 (2d ed. 1970) [hereinafter T. KuhN, ScienTIFIC Revolutions].

After the publication of Scientific Revolutions in 1962, some commentators noted that Kuhn had used the term "paradigm" in several different ways. See, e.g., Margaret Masterman, The Nature of a Paradigm, in CRITICISM AND tHE GrowTH of KNowledge 59 (I. Lakatos \& A. Musgrave eds., $3 \mathrm{~d}$ ed. 1974). Kuhn accepted the basic point and responded by distinguishing between paradigm as "disciplinary matrix" and paradigm as "exemplar." Thomas S. Kuhn, Second Thoughts on Paradigms, in The Structure of Scientific Theories 463 (F. Suppe ed., 2d ed. 1977). An exemplar is a concrete problem, together with its solution, that serves as "a community's standard example[]." Id. at 471. A disciplinary matrix is an entire set of shared symbolic representations, models, exemplars, values, and "other elements of the sort." Thomas S. Kuhn, Reflections on My Critics, in CRITICISM AND THE GROwTH OF KNOwLeDge, supra, at 271-72 [hereinafter Reflections]. This coincides with what I would call a "subculture" or what Richard Rorty calls a "normal discourse." RICHARd RoRTY, PHILOSOPHY AND THE MIRROR OF NATURE 320 (1979). In this sense, "paradigm" shades into the broader use of the Kuhnian term "normal science."

There is a common third usage, which refers to the conceptualization that is abstracted from an exemplar. This usage coincides with what Kuhn calls a "model": "Models . . . are what provide the group with preferred analogies or, when deeply held, with an ontology." Kuhn, Second Thoughts on Paradigms, supra, at 463. I shall be using the term "paradigm" to refer both to models and to disciplinary matrices without pausing to distinguish between them. 
ory is special."45 Indeed, it would mean that "everything is theory."46

Fish's argument fails him here, and in obvious ways. The most obvious problem is one of circularity. Theory, he argues, is a special kind of thing that stands above practice and directs it-something which cannot be done and, therefore, does not matter. But if we were to redefine theory to include things that can be done and do have consequences, then theory would no longer be special. We shall return to this point in the next section, where we shall consider why Fish might take such a strange position.

The other problem is less obvious but equally devastating: Fish answers the wrong question. Why consider only the subsequent work pursuant to a powerful paradigm and not the paradigm itself? Maybe the imitations of a powerful new paradigm are better characterized as "practice." But what about the development of new paradigms and generalizations? If someone comes up with a new explanation of how readers read, how meanings are generated, or how law is constructed-an explanation that will then be adopted and imitated by others, or that will inform practice-why isn't that "theory"?

Fish just never considers this question. But he does consider the everything-is-theory position. As he recognizes, this position is itself a variant of the antifoundationalist insight: Because a practice is only meaningful against a set of contingent background assumptions, in a sense every practice is "underwritten by theory." 47 Fish responds by reinforcing the point that practice and theory are distinct: "Am I following or enacting a theory when I stop for a red light, or use my American Express card, or rise to speak at a conference?" 48

With this counterargument, however, Fish addresses the nagging question: Isn't the process of exposing the contingent background assumptions that make practice intelligible in some sense "theory"? $\mathrm{He}$ identifies both weak and strong versions of this claim. Fish rejects the weak version because it is neither sufficiently reliable nor sufficiently distinct. He acknowledges that we can "get a perspective on some of our beliefs in relation to some others," and that this in turn may prompt us to change our beliefs. "The trouble is, such reconsiderations can be brought about by almost anything and have no unique relationship to something called "theory." "49

Fish rejects the strong version for more powerful reasons. "The strong claim reinvents foundationalism because it imagines a position from which our beliefs can be scrutinized; that is, it imagines a position outside belief, the transcendental position assumed and sought by the-

45. Consequences, in Doing What Comes Naturally, supra note 2, at 326.

46. Id. (emphasis in original).

47. Id.

48. Id. at 327 .

49. Id. at 332 (emphasis in original). 
orists ...."50 This, of course, is his argument against antifoundationalist theory hope. But the response now is stronger: It is not just that antifoundationalist theory hope ultimately fails; it cannot even get off the ground.

$[R]$ eflection requires a space in which it can occur, and ... that ... space of reflection cannot already be occupied by what are to be its objects .... [But] if reflection must occur in a place or moment apart from the "prevailing realm of purposes," and if the first thesis of critical thought is that the "prevailing realm of purposes" covers the field, then reflection can never get off the ground because it is always tethered to the ground from which it claims to set us free. ${ }^{51}$

We have now come to the complete and final defeat of theory; one cannot theorize because even self-conscious reflection is impossible. ${ }^{52}$

The conclusion would be absurd if it were not so charmingly paradoxical. The antifoundationalist insight teaches that we can only believe what we believe. In Fish's own words:

[B]eing situated not only means that one cannot achieve a distance on one's beliefs, but that one's beliefs do not relax their hold because one "knows" that they are local and not universal. This in turn means that even someone ... like me ... who is firmly convinced of the circumstantiality of his convictions will nevertheless experience those convictions as universally, not locally, true. ${ }^{53}$

You may find it surprising that, after all this sophisticated antifoundationalism, we are left only with primitive belief. Here, we may return to Bull Durham for instruction. As Annie Savoy (played by Susan Sarandon) ruefully observes of Nuke and his success in the major leagues: "The world was made for people who aren't cursed with selfawareness."

\section{B. The Worm at the Heart of Being Fish}

The fissures that we have opened in our rehearsal of Fish's argument in the previous subsection are symptomatic of a more fundamental flaw foreshadowed in Part I: For all his antifoundationalist fervor, Fish is still a captive of objectivism. ${ }^{54}$ And it gets worse. Without the buttress of his crypto-objectivist assumptions, Fish's arguments against theory and against critical self-consciousness are flat and unpersuasive.

Now, obviously, Fish would be astonished to be called a crypto-objectivist. But his entire argument rests on a surprisingly restricted repertoire of rationalist moves. Fish's reliance on objectivist assumptions

50. Id. at 331 .

51. Critical Self-Consciousness, in Doing What Comes Naturally, supra note 2, at 455.

52. Id. at 467.

53. Id.

54. Cf. Schlag, supra note 37, at $938 \mathrm{n} .40$ ("Indeed, at times, his arguments seem steeped in Kant ....") (discussing Fish's argument against Mark Kelman in Dennis Martinez, quoted in text accompanying note 23 supra). 
is immediately evident when he opts for purely objectivist parameters in his definition of "theory." One might defend this choice on the ground that Fish is mounting an internal critique, taking objectivism on its own terms and showing that its project is impossible. ${ }^{55}$ But this interpretation is belied by his actual arguments. Fish will not accept that the process of developing and applying new empirical generalizations or paradigms can be called "theory." He cannot accept this designation because, as he plaintively puts it, "we will have lost any sense that theory is special." 56 Why theory must be special is never made clear. More to the point, why it must be special in the way assumed by objectivists - that is, above and outside practice, providing a formula that guides and determines practice's every move-is never made clear either. Why isn't it "theory" when a new paradigm or conception operates to structure and inform practice in the familiar self-reflective way? If the objectivist claim for theory can never be redeemed, why not recognize a conception of theory that is in the realm of human possibility? Fish's blindness to other conceptions of theory is, in part, the cost of defining himself in opposition to what he purports to reject. ${ }^{57}$

But this is only a surface manifestation; the problem is still deeper. Like most other antifoundationalists, Fish has rejected only half the apparatus of objectivism. Although he has firmly rejected the foundational framework, he has nevertheless maintained the entire infrastructure that is the content of the objectivist model of rationality. This important point will not be self-evident because, within the Western tradition, the objectivist model of rationality is understood to be the form and essence of reason. ${ }^{58}$ Accordingly, the point requires elaboration.

"' 'Reason,' as the term is used in the Platonic and Kantian traditions, is interlocked with the notions of truth as correspondence, of knowledge as discovery of essence, of morality as obedience to princi-

55. Cf. Adena Rosmarin, On the Theory of "Against Theory," in Against Theory 86 (W. Mitchell ed. 1985) (arguing that Fish is a rhetorician who merely borrows the style of philosophy for persuasive effect).

56. Consequences, in Doing What Comes Naturally, supra note 2, at 326.

57. Fish's favored self-description, after all, is as an antifoundationalist. He only occasionally describes himself as a conventionalist or interpretivist and, as far as I can tell, never as a social coherentist or relativist. It is rather like the analysand who rejected the therapist's insight that she was powerfully influenced by her mother. "That's not true!" she said. "I am nothing like my mother. In fact, I am exactly the opposite!" (Personal communication with analysand.)

For a thoughtful discussion of the problems with defining one's identity negatively, see Guyora Binder, Representing Nazism: Advocacy and Identily at the Trial of Klaus Barbie, 98 YAL.E L.J. $1321,1339-55,1372-83$ (1989) (criticizing the various attempts of the French, the Israelis, post-Holocaust Jews, and Jacques Derrida to define themselves in opposition to Nazism).

58. George Lakoff, Women, Fire, and Dangerous Things: What Categories Reveal. ABout THE Mind xvii (1987) ("The objectivist view rests on a theory of categories that goes back to the ancient Greeks and that even today is taken for granted as being not merely true, but obviously and unquestionably true."). 
ple ...."59 This particular network of associated beliefs is not accidental, but rather systematically related to the position that defines objectivism. The basic objectivist belief is that the world is made up of determinate, mind-independent objects with inherent characteristics or "essences." 60 Reason is considered to be a faculty that strives to represent those objects in a linear, undistorted fashion by means of propositions that describe their properties and relations. Categories are organized in terms of the common properties that are the necessary and sufficient criteria of membership. Distinctions are the logical means by which we discriminate between apparently similar things that "in fact" fall under different concepts. Principles are high-order generalizations which serve as fundamental laws that accurately characterize essences or relationships.

Much of this may seem self-evident because it characterizes so much of what we assume rationality is about. But it is only the paraphernalia of objectivism. Undermine the foundational assumption-i.e., that it is the "true" objects of the world about which we reason-and the entire apparatus falls with it. As Fish puts it, "remove the connection between observable features and the specification of meaning, and you also remove everything else that is supposedly independent of context; entailment [and] contradiction . . . become as variable and contingent as presupposition."61 But, (and here's the catch) if the antifoundationalist insight is correct-if reason is not grounded in the observable, objective facts of the world-then there is no reason to assume that rationality issues in propositions, that things have determinable essences, that distinctions of kind are a basic unit of logic, or anything else. If reason is solely the product of historical and cultural forces, as Fish claims, then it should be "variable and contingent" in form as well as substance. It may be "[a] mobile army of metaphors, metonymies, anthropomorphisms," 62 or characterized by free play, ${ }^{63}$ or structured in yet other ways that we shall explore.

Thus, it is more than a little surprising to find that Fish frequently invokes the same old rationalist repertoire when he describes the nature of reason within an interpretive community.

[Y] ou will always be guided by ... the content of any settled practice, by the assumed definitions, distinctions, criteria of evidence, measures

59. Richard Rorty, Pragmatism, Relativism, and Irrationalism, in Consequences of PragMATISM 172 (1982).

60. The objectivist "begins with the natural kind as it is found in the world, arguing that ... meaning comes from the natural kind's essential nature as it exists in the world." Michael S. Moore, The Interpretive Tum in Modern Theory: A Turn for the Worse?, 41 STAN. L. REv. 871, 879 (1989).

61. The Anti-Formalist Road, in DoIng What Comes Naturally, supra note 2, at 2.

62. FrIedrich NieTzSCHe, On Truth and Falsity in Their Ultramoral Sense, in The CompLete Works of Friedrich Nietzsche 80 (O. Levy ed., M. Magge trans. 1974).

63. Jacques Derrida, Structure, Sign and Play in the Discourse of the Human Sciences, in WRITING AND DiffERENCE 292 (A. Bass trans. 1978). 
of adequacy, and such ....64

[A]ny skepticism one "developed" would have a content . . . which would presuppose some set of already-in-place distinctions, hierarchies, values, definitions . . . ${ }^{65}$

[R]eason cannot operate independently of some content-of some proposition or propositions made up of definitions, distinctions, and criteria already assumed . . . ${ }^{66}$

But he never explains why reason must take the particular form assumed by the objectivist model of rationality. ${ }^{67}$

This is no mere pedantic point for, as I intend to establish, it goes to the very heart of Fish's critique of theory. My argument against Fish turns on two interrelated demonstrations. In the balance of this section, I show that Fish's arguments against theory and self-consciousness are entirely dependent on his assumption of the apparatus of objectivist rationality. In the next section, I use his own arguments to show that the objectivist model of rationality is not the only possible description of how humans reason. Indeed, as I have argued elsewhere, it is not even a very good one. ${ }^{68}$

Perhaps the single most identifying characteristic of the objectivist model of rationality is the "law of contradiction" that flows from the belief in essences. This is expressed by the conventional tautology of formal logic: $P$ or $\sim P$ (not-P). Thus, an object either has a property or it does not. Either a proposition or its negation must be true, but not both. This axiom is "the law of the excluded middle"; no alternatives other than $\mathrm{P}$ or $\sim \mathrm{P}$ exist. ${ }^{69}$

But all this follows only if one accepts the essentialist position. Once one sees meaning as contextual, the same proposition will be true and false in different contexts. ${ }^{70}$ Moreover, once one rejects essentialism, differences need no longer be hard-edged, all-or-nothing affairs. Instead, differences are not only relativized to context, but also relativized in content. When a manufacturer markets a defective product is it a contract issue or a tort issue? Where, indeed, is the boundary between contract and what lies beyond (such as tort)? For a nonobjectiv-

64. Consequences, in Doing What Comes Naturally, supra note 2, at 323.

65. Critical Self-Consciousness, in DoING What Comes Naturally, supra note 2, at 440.

66. Force, in Doing What Comes Naturally, supra note 2, at 518-19.

67. It is not, I might repeat, that Fish has no other choices but the objectivist model. At the very least, there is always the instrumental rationality of purpose. See, e.g., Fish $v$. Fiss, in Doing What Comes Naturally, supra note 2, at 127 (one is situated in "a field already organized by problems, impending decisions, possible courses of action, goals, consequences, desiderata, etc.").

68. See Winter, supra note 26 , at $1129-59$

69. Id. at 1148; see also Jennifer Jaff, The Difference that Difference Makes, 19 CumB. L. Rev. 467,470 n.10 (1989) ("This form of logic in which 'P or not $P$ ' is thought to be irrefutable dominates Western thought.").

70. For most Americans, the proposition "killing is immoral" is always true except for state-sanctioned executions. Or self-defense. Or national security. Note that we have already entered the domain of "split proliferation." See Schlag, supra note 37, at 942-44; Winter, supra note 26 , at $1124-25$ n.69. 
ist, these questions can have no definitive answers. ${ }^{71}$ The world can no longer be assumed to be organized naturally according to the rigors of $\mathrm{P}$ or $\sim \mathrm{P}$. Categories like contract and tort-or theory and practicecan no longer be taken as fixed, nonredundant groupings of homogeneous entities or activities. Instead, the rational world is characterized by probabilities, continua, fluidities, and indistinct shades. Choices abound, and definitional certainties are hard to come by.

But Fish has no patience for fluidity. Rather, the entire logic of his argument against theory is built on essentialist rigors. It starts with his $\mathbf{P}$ or $\sim \mathbf{P}$ definition of theory as entirely separate from or extrinsic to practice. Indeed, Fish directly applies the logic of $P$ or $\sim P$ to reject the argument that the development of a new paradigm or useful generalization is "theory." It "would be to blur the distinction between theory and everything that is not theory ...."72 Thus, only objectivist theory is real theory. To include innovative paradigms and generalizations as theory would be to deny the essence of theory: that it is special.

In his other arguments against theory, Fish is equally dependent on the all-or-nothing gambit. Thus, he rejects the argument that empirical generalizations are theory, because that would mean that "everything is theory." "73 (But what about using one's American Express card?) The process of exposing the contingent background assumptions that ground practice cannot be called theory for the converse reason. It may be, he acknowledges, that critical examination of beliefs will yield the insight that a particular belief has no foundations. This insight, in turn, may prompt someone to reconsider his or her practices. But, Fish responds, "such reconsiderations can be brought about by almost anything and have no unique relationship to something called "theory." "74 In other words, critical examination bears no essential or necessary relation to change in beliefs; because change in beliefs can be caused by anything, critical examination is insufficiently distinct as an entity to be identified as "theory." For Fish, there are only all-or-nothing, hardedged distinctions of the form $\mathrm{P}$ or $\sim \mathrm{P}$; if a distinction is not absolute and categorical, it is not a distinction at all. ${ }^{75}$

71. See generally Jay M. Feinman, The Jurisprudence of Classification, 41 STAN. L. REv. 661 (1989) (exploring the nonobjectivist nature of legal classification in the context of the distinction between contract and tort as applied to product liability). added).

72. Consequences, in Doing What Comes Naturalid, supra note 2, at 325 (emphasis

73. Id. at 326 (emphasis in original).

74. Id. at 332 (emphasis added).

75. Fish is not the only antifoundationalist afflicted with this problem. Derrida was asked by Gerald Graff whether he didn't run the risk "of keeping certain linguistic superstitions alive in order to legitimate the project of calling them into question?" Afterword to JACgues DeRrida, Limrted INC 115 (S. Weber \& J. Mehlman trans. 1988). Derrida responded that: "Every concept that lays claim to any rigor whatsoever implies the alternative of "all or nothing.' "Id. at 116; accord id. at 117 ("But it is true, when a concept is to be treated as a concept $I$ believe that one has to accept the logic of all or nothing. I always try to do this and $I$ believe that it always has to be done...."). The vehemence seems only to underscore the problem. 
It should be clear that this is not a momentary lapse on Fish's part, but rather a consistent and repeated strategy. Consider Fish's treatment of the claim-made variously by Owen Fiss, Wayne Booth, and Stephen Toulmin-that one can escape "the parochial, the interested, the partial, [or] the partisan" by the exercise of "impartial rationality" or "self-conscious reflection."76 Fish rejects this claim because "the specification of what is and is not an 'impartial manner' is itself an 'interested' act, that is, an act performed within a set of assumptions" about what constitutes impartiality. ${ }^{77}$ That the concept of impartiality is socially constructed is, I think, correct. But it certainly does not follow that it is not worth striving for. Fish acknowledges this, but only momentarily: "[T]here is certainly a difference between 'acting impartially' and acting in the name of one's preferences, but the difference is between different forms of interest-laden behavior . . .."78

In this last argument, Fish invokes not one but three related objectivist gambits. First, he assumes that the only differences which matter are differences of kind; he obliterates differences of degree (or at least declares them theoretically uninteresting). ${ }^{79}$ Second, and more subtly, Fish employs the word "interest" as if it had only a single, nonpolysemous meaning. That, of course, is only true if the word-category "interest" is subject to the objectivist rigors of $P$ or $\sim P .{ }^{80}$ This totalizing use of "interest" elides the critical point: that there is an important difference between acting in one's own self-interest and acting in a way that is "interested" only in the sense that it is socially constructed. This elision is his third, most hidden objectivist move. A socially constructed "impartiality" is only to be faulted if one is holding out for something more, such as the truly objectivist, transcendent position that Fish demonstrates is impossible.

The all-or-nothing maneuver is also the engine of Fish's argument that critical self-consciousness cannot help effectuate change. Once again, his strategy is to insist on an essential or necessary relationship between the invocation of critical self-consciousness to effect persuasion and its actual success in prompting change. ${ }^{81}$ Similarly, he invokes

76. Crilical Self-Consciousness, in Doing What Comes Naturally, supra note 2, at 438-41.

77. Id. at 439 .

78. Id.

79. "[W] hile such moments are certainly possible (we can and do think in a critical way about what we're doing, whether it be science or literary criticism or lawyering), they are not insulated from, but are a function of, the deeply assumed norms and standards that are the grounds of possibility of any moment, including those named 'deliberation' or 'reflection.' " Id. at 440-41. This argument, of course, demonstrates only that there is no transcendental standpoint. It is not an argument that critical self-consciousness is impossible or worthless.

80. This, of course, is something Fish must reject, because for him meaning is "never a function of formal linguistic structures." Dennis Martinez, in Doing What Comes Naturally, supra note 2, at $581 \mathrm{n} .2$ (discussed at notes 17-18 supra and accompanying text).

81. "[C]hange cannot be engineered because persuasion is a contingent rather than a formal matter. There exists no certain correlation between the exertions of persuasive pressure (of whatever kind) and the certainty or even the likelihood of success." Critical Self-Consciousness, in Doing What Comes Naturally, supra note 2, at 463 (emphasis added). By the 
the totalizing move in his argument that the antifoundationalist insight cannot be liberating. He denies that "there are degrees of constraint, or, more precisely, that there is a continuum on which forms of thought and social organizations can be ranked ...."82 Rather, he boldly asserts that there is no continuum because "the degree of constraint-at least in relation to an ideal condition of freedom-is always the same and always total." 83

Once we have exposed the all-or-nothing structure of Fish's rhetoric and the objectivist assumptions from which it derives, the arguments that it supports lose their persuasive force. Why must all liberation and constraint be measured against an "ideal condition of freedom"? This is only " $[t]$ he rationalist's dilemma: either the free act is possible, or it is not-either the event originates in me or is imposed on me from outside . . ."84 But as situated selves capable of reflection, we can recognize our own historicity and reconceptualize freedom in more meaningful terms. As Merleau-Ponty explains:

I am a psychological and historical structure, and have received, with existence, a manner of existing, a style. All my actions and thoughts stand in a relationship to this structure. ... The fact remains that I am free, not in spite of, or on the hither side of, these motivations, but by means of them. ${ }^{85}$

Indeed, it would seem at first that Fish agrees: "[O]ur freedom is a function of -in the sense of being dependent on-some other structure of constraint without which action of any kind would be impossible."86 But he immediately reverts to the rationalist logic of $P$ or $\sim P$ and asserts that "it follows . . . that there can be no continuum which differentiates institutions or structures as being more or less constrained, more or less free, because freedom, in whatever shape it appears, is another name for constraint."87

But what if we were to take seriously the notion that these "constraints" provide the enabling conditions of possibility? We would un-

same token, there may be "no certain correlation" between trying to catch the corner of the plate with a curve ball and succeeding. But it is certainly related to one's knowledge of how to pitch; it will help to grip the ball a certain way, etc.

82. Id. at 459 .

83. Id. (emphasis added).

84. Maurice Merleau-Ponty, The Phenomenology of Perception 442 (C. Smith trans. 1962).

85. Id. at 455 .

86. Critical Self Consciousness, in Doing What Comes Naturally, supra note 2, at 459 .

Compare Merleau-Ponty's rejoinder to Sartre:

It is true that I can at any moment interrupt my projects. But what is this power? It is the power to begin something else, for we never remain suspended in nothingness.

We are always in a plenum, in being .... I may defy all accepted form, and spurn everything, for there is no case in which I am utterly committed: but in this case I do not withdraw into my freedom, I commit myself elsewhere. Instead of thinking about my bereavement, I look at my nails, or have lunch, or engage in politics.

M. Merleau-Ponty, supra note 84 , at 452 (emphasis in original).

87. Critical Self-Consciousness, in Doing What Comes Naturally, supra note 2, at 459. 
derstand that situatedness "does not limit [our] access to the world, but on the contrary is [our] means of entering into communication with it." 88 The focus would then be on the different experiences that are enabled. "Taken concretely, freedom is always a meeting of the inner and the outer ... and it shrinks without ever disappearing altogether in direct proportion to the lessening of tolerance allowed by the bodily and institutional data of our lives." 89 There is, for example, an obvious and important difference between the degree of constraint experienced by the adherent of a strict religious faith and that experienced by the typical member of secular culture: (I know; I've been there.) ${ }^{90}$ Both ways of being in the world are socially constructed, and in one sense they are thus equally constraining. But in a more significant sense-and the only sense that can matter for us as situated humans-they are not. Similarly, the artist and the housepainter, the law professor and the legal secretary, are all constituted in part by their social roles. But they experience neither the same constraints nor the same possibilities of creativity and expression.

"It is clear what a summary rationalism might say to such a hybrid notion: there are no degrees of possibility ...."91 But, in an antifoundationalist world, one asks neither for absolutes nor for certainties. All one has are possibilities; either they are taken up and maximized, or they are not. Thus, Fish is correct that persuasion cannot be reduced to a mechanical, linear process-as I have argued elsewhere. ${ }^{92}$ But as a lawyer, I have happily consulted theory and selfconsciously constructed arguments calculated to increase my chances. ${ }^{93}$ We can always call such imitations of a powerful theory "practice," but we will have lost a sense of the value of considered human interaction with a real, often difficult world.

In the end, Fish's version of antifoundationalism is to real life as most movie-baseball is to real-world baseball: It lacks nuance.

The strikeout may in fact be said to symbolize where most baseball movies go wrong.... Of the rich gray diet of bleeders and ropes and humpbacked liners that constitute the real game, a movie fan would

88. M. MERLEAU-PONTY, supra note 84 , at 455 .

89. Id. at 454 (emphasis in original).

90. The imaginative power of these constraints can be quite compelling, as illustrated by a friend's account of the first time he violated the Sabbath. He got into his car on a Saturday afternoon and put the key in the ignition. As he told it to me: "I was afraid to turn it. I sat there shaking," and here he turned his head as if to look over each shoulder, "literally waiting for the lightening to strike." My own experience of the shift was less colorful, but then I am a relatively deliberate, reflective person.

91. M. Merleau-Ponty, supra note 84 , at 442 .

92. See Winter, supra note 2 , at 2244-45, 2252-55, 2271-79.

93. In The Cognitive Dimension, I describe strategies of persuasion that are informed by a nonobjectivist, cognitive theory of how humans imaginatively construct social meanings by the use of metaphors, metonymies, and idealized cognitive models. Id. at 2271-79. I have decided not to provide specific examples from my practice, for fear that the reader might crack under the weight of yet another immodesty. For those who require sources, however, I provide the following parenthetical: (Anecdotes on file with author). 
know nothing. Nor would he begin to guess the magic chasm that lies between connecting safely 25 percent of the time and 35 percent, or between winning two games out of five and winning three. It's hard to film modulations, and baseball is made of modulations. ${ }^{94}$

Fish's arguments never allow for differences of degree, but those are the only differences that are interesting. The task of theory is not to end all modulations with a determinate formula to govern practice. Rather, the task of theory is to explore "the magic chasm," to characterize the nuances and contingencies in ways that are usefully predictive and that enable more considered action. What I hope the preceding discussion has shown is that, for this project, we will need a very different concept of rationality.

\section{Don't Think Twice, It's Alright}

There is, of course, one obvious rejoinder to my critique. Invoking a variant of the response rehearsed in Part I, Fish might say something like this: "Okay. So you have shown that my arguments employ the apparatus of objectivist rationality. Big deal. You yourself acknowledge that it is the dominant mode of reasoning 'within the Western tradition.' After all, I am situated in that tradition just like anyone else. What other form of rationality could I use?" But this rejoinder is only perspicuous within the assumptions indulged by Fish. It assumes that the only source of meaning is cultural, and it indulges the very unreflectiveness that Fish is trying to justify.

A more reflective understanding of our use of language, however, provides a more powerful model of rationality. ${ }^{95}$ I will use Fish's own arguments to demonstrate this alternative. In other words, the short answer to Fish's hypothetical rejoinder-"What other form of rationality could I use?"- -would be: "The one you are already using so unreflectively."

In the Western tradition, reason has always been a rather disembodied affair. But, on further reflection, the insight about situatedness suggests that there is an even more rudimentary way in which we are always and already situated: Reason is a faculty of embodied social creatures situated in a relatively stable physical environment. There

94. Wilfrid Sheed, Why Can't the Movies Play Ball?, N.Y. Times, May 14, 1989, \& 2 (Arts \& Leisure), at 1, 14 col. 5 (noting Bull Durham as the outstanding exception); accord Roger Angell, No, But I Saw the Game, THE NEw Yorker, July 31, 1989, at 41 ("Real baseball drama takes its time, ... and its thrilling or melodramatic resolutions tend to be minor events. ..."); id. at 44 (" 'Bull Durham' . . offers almost the first evidence that the phrase 'baseball movie' is not an oxymoron.").

95. The major explanations of these recent developments in cognitive theory are presented in G. Lakoff, supra note 58, and in Mark Johnson, The Body in the Mind: The Bodily Basis of MEANIng, Imagination and Reason (1987). I have provided more comprehensive accounts elsewhere. See Winter, supra note 2, at 2230-55; Winter, The Metaphor of Standing and the Problem of Self-Governance, 40 STAN. L. REv. 1371, 1382-86, 1491-97 (1988); Winter, supra note 26 , at $1129-59$. 
are some embodied experiences like movement through space toward desired objects, the use of tactile and visual perception to gain information about the world, and the capacity of some objects (like our bodies) to contain other objects (our insides) that are common and basic to the species. It is in the framework formed by these embodied experiences that we are most powerfully situated.96

All this seems quite counterintuitive from within the Western tradition, with its emphasis on Reason as a transcendent faculty and distrust of the body and perception. ${ }^{97}$ But there is nothing surprising in the insight that human rationality involves generalization; accordingly, there should be nothing surprising about the notion that reason begins with generalization or imaginative abstraction from embodied experience. ${ }^{98}$ Meaning is a human construction that begins with the generalization of rudimentary interactions with the world, like movement through space toward desired objects or tactile and visual perception. Each of these generalizations is a mental construct (if you prefer, an interpretive construct like Kelman's broad or narrow time frames ${ }^{99}$ ) that provides structure to human thought and a measure of apparent unity and determinacy in our experience of the world. ${ }^{100} \mathrm{I}$ say "appar-

\begin{abstract}
96. Compare, once again, Merleau-Ponty's response to Sartre:
Whether or not I have decided to climb them, these mountains appear high to me, because they exceed my body's power to take them in its stride, and ... I cannot so contrive it that they are small for me. Underlying myself as a thinking subject, who am able to take my place at will on Sirius or on the Earth's surface, there is, therefore, as it were a natural self which does not budge from its terrestrial situation.... What is more, my projects as a thinking being are clearly modelled on the latter; if $I$ elect to see things from the point of view of Sirius, it is still to my terrestrial experience that I must have recourse in order to do so.... In so far as I have hands, feet, a body, I sustain around me intentions which are not dependent upon my decisions and which affect my surroundings in ways which I do not choose. These intentions are general . . . in the sense that they are not simply mine, they originate from other than myself, and I am not surprised to find them in all psycho-physical subjects organized as I am.
\end{abstract}

M. MERLEAU-PontY, supra note 84 , at 440.

97. See, e.g., David Hume, Enquiries Concerning Human Understanding and Concerning the Principles of Morals 151-55 (L. Selby-Bigge 3d ed. 1975) (1748); Plato, Phaedo, in Great Dialogues of Plato 531, 597 (W. Rouse trans. 1970). This bias in favor of transcendent Reason is not accidental, but has its source in our fear of mortality: "To the extent that it is rooted in biological existence, our personal existence is inherently precarious; yet we hide this precariousness from ourselves by mostly repressing the organism and reducing the past to a collection of ideas or images." Monika M. Langer, Merteau-PonTy's PheNOMENOLOGY OF PERCEPTION: A Guide AND CommentaRY 33 (1989).

98. Cf. M. MERLEAU-PonTY, supra note 84, at 84: "Just as we speak of repression in the limited sense when I retain through time one of the momentary worlds through which I have lived, and make it the formative element of my whole life-so it can be said that my organism, as a prepersonal cleaving to the general form of the world, as an anonymous and general existence, plays, beneath my personal life, the part of an inborm complex." (Emphasis in original.)

99. See Mark Kelman, Interpretive Construction in the Substantive Criminal Law, 33 Stan. L. Rev. 591, 593-94 (1981).

100. M. Johnson, supra note 95, at 29; $c$. Immanuel Kant, Critique of Pure Reason 182 (N.K. Smith trans. 1929) ("No image could ever be adequate to the concept of a triangle in general. It would never attain that universality of the concept which renders it valid of all 
ent" because, although these basic constructs arise from embodied experiences of the human organism in the world, they say nothing about the nature of the world itself. ${ }^{101}$

Thus, the experience of movement through space toward desired objects is conceptualized as a source-path-goal schema and a metaphor (PURPOSES ARE DESTINATIONS). 102 The bounded nature of our bodies, as well as other container-objects, is conceptualized as a container schema with an in-out orientation. ${ }^{103}$ By these cognitive means, embodied experiences form the bases of a nonobjectivist rationality that is elaborated imaginatively by metaphor, by metonymy, and by the extension of socially constructed, idealized cognitive models. ${ }^{104}$

We use these cognitive processes unreflectively to structure more abstract domains. For example, tactile and visual perception are each the source domain of a metaphor that is part of a metaphorical system-sometimes referred to as the conduit metaphor ${ }^{105}$-by which we conceptualize mind, ideas, knowledge acquisition, and the communication of knowledge to others. The development is from the experientially concrete domain of physical manipulation of objects to the

triangles .... The schema of the triangle can exist nowhere but in thought. It is a rule of synthesis of the imagination. ...").

101. See Nelson Goodman, Ways of Worldmaking 2-3 (1978) ("If I ask about the world, you can offer to tell me how it is under one or more frames of reference; but if I insist that you tell me how it is apart from all frames, what can you say?"); HILARY PUTNam, REAson, TRUTH AND HISTORY 54 (1981) ("there are ... [no] inputs which are not themselves to some extent shaped by our concepts") (emphasis deleted); Winter, supra note 26, at 1130-34; see also note 104 infra. This point is critical, because the experientialist claim is sometimes misread as a reintroduction of objectivism or empiricism.

102. This is what makes sense of common expressions like: "My project is pretty far along: I can see the light at the end of the tunnel." For further examples, see Winter, supra note 26, at 1132-33, and Winter, supra note 2, at 2232, 2235-40.

103. See Winter, supra note 26 , at $1147-48,1150-51$.

104. This is a more complex view of reason than we are used to, but it has the distinct advantage of escaping the tyranny of the subject/object dichotomy that characterizes objectivist and antifoundationalist views alike. Despite its apparently universalist form, this model of reason is nevertheless nonobjectivist and culturally relativist in substance. It is nonobjectivist, because a rationality that is imaginatively elaborated through mediating devices such as metaphor and cognitive models does not have direct access to states of affairs in the world. It is relativist for much the same reason: "[S]ince an indirectly understood concept may be elaborated in more than one way, there is more than one way to understand the world." Winter, supra note 26 , at 1134 .

This account, moreover, both agrees with Fish and explains the power and importance of the insight that we are always culturally situated: Because we are embodied social creatures always situated in a variable social environment, the social experiences of different cultures are the source domains for different cognitive models. These models, in turn, become the bases for apprehending the world in different ways. For examples, see Winter, supra note 26, at 1133 n.95 \& 1134 n.96; Winter, sufra note 2, at 2253-54; and Eve E. Sweetser, The Definition of lie: An Examination of the Folk Models Underlying a Semantic Prolotype, in CULTURAL Models in Language and Thought 43, 60-62 (D. Holland \& N. Quinn eds. 1987).

105. So called because this metaphorical system conceptualizes ideas as objects and words as containers that are sent to the audience who gets the meaning out of the words. See Michael J. Reddy, The Conduit Metaphor-A Case of Frame Confict in Our Language about Language, in METAPHOR AND ThOught 284, 286-92 (A. Ortony ed. 1979); see also George LaKofF \& MARK JohNSON, MEtaphors We Live By 10-12 (1980). 
abstract domain of cognitive "manipulation" of reified "objects." Consider the following common metaphors for mental activity, each illustrated with a few examples ${ }^{106}$ :

IDEAS ARE OBJECTS-What are the building blocks of your theory? That is food for thought; I want to tum it over in my mind before I'm sure.

THE MIND Is A CONTAINER-Is that what you had in mind? I knew he'd talk; he always spills the beans.

UNDERSTANDING IS GRASPING-That last point is hard to grasp; I always have difficulty getting $a$ handle on that phenomenology stuff.

COMMUNICATION IS SENDING-She delivered a brilliant lecture, but the students prefer to be spoon-fed.

KNOWING IS SEEING-What's your view on this? I didn't get your explanation at first, but now I see it. 107

This particular set of conceptual metaphors is systematic in Western language and culture. ${ }^{108}$ The etymological development of ordinary English words for mental activity reflects precisely the cognitive process described above. Thus, we find the following etymological trajectories from Latin to English ${ }^{109}$ :
$e x+$ agmen (pull out from a row)
$\longrightarrow \quad$ examine
cipere (to take)
percipere (to lay hold of)
$\longrightarrow \quad$ perceive
scrutari (to pick through trash)
$\begin{array}{ll}\longrightarrow & \text { scrutinize } \\ & \text { comprehend }\end{array}$
com + prehendre (to grasp together)
propose
proponere (to set forth)
propound
propositio (a setting forth) proposition

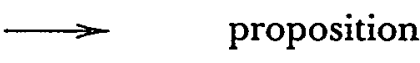
trans + ferre (to carry over)

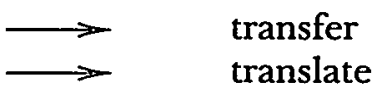
trans + latus (past participle of ferre) $\longrightarrow \quad$ translate

106. The examples are adapted from Lakoff and Johnson. G. LAKOFF \& M. JoHNSON, supra note 105, at 10-11, 46-48; G. LAKOFF, supra note 58, at 450. Reddy lists 141 examples. Reddy, supra note 105, at 311-320.

107. The metaphors undERSTANDING IS GRASPING and KNOwing Is SEEING can also be combined to yield a perfectly comprehensible mixed metaphor, as in: "The purpose of this faculty meeting is to take a look at the student proposal."

108. Eve Sweetser, From Etymology to Pragmatics: The Mind-As-Body Metaphor in Semantic Structure and Semantic Change (forthcoming 1990). Sweetser traces a pattern of semantic development in several Indo-European languages; she demonstrates that, despite different linguistic expressions, all of these languages employ this system of conceptual metaphors.

109. The etymologies are as given in E. SweEtSER, supra note 108, and The Random House Dictionary of the English Language, supra note 28. 
An equivalent example is the development of the word "metaphor" from the Greek meta pherein (to carry over).

The entire, cherished apparatus of objectivist rationality turns out to be metaphorically structured. A proposition is the means by which we take our reified ideas (IDEAS ARE OBJECTS) and present them (COMMUNICATION IS SENDING) in a linear fashion (source-path-goal schema)..$^{10}$ Similarly, objectivist categorization according to common properties is premised on a conception of categories as metaphoric containers. ${ }^{111}$ This use of the container schema to structure the concept "category"112 leads to the inference that categories have well defined boundaries. This in turn yields the distinction as a dichotomous choice between $\mathrm{P}$ or $\sim \mathrm{P}$, as illustrated in the accompanying figure. Thus, the most cen-

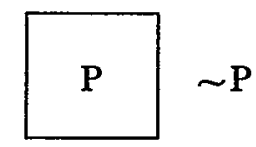

\section{Categorization and $\mathrm{P}$ or $\sim \mathrm{P}$ as container metaphor}

tral aspects of objectivist rationality are imaginative, metaphoric products of the container schema or, in other words, the result of a construct we impose on the world.

Now Fish uses all the same, conventional constructs as the rest of us. We have already seen his reliance on the container schema in his repeated and insistent use of $P$ or $\sim P$. Similarly, as we saw earlier, ${ }^{113}$ much of his argument against objectivist theory and critical reflection is constructed by privileging the container schema.114 Thus, "history is the context within which we know." 115 Theory "is an attempt to guide practice from a position above or outside it."116 But one is always and "already embedded in the context of assumptions and practices," 117 in fact

110. And, thus, a bad or confused idea is convoluted.

111. See, e.g., Richard A. Posner, The Jurisprudence of Skepticism, 86 Mrch. L. Rev. 827, 83031 (1988) (noting the role of "the metaphor of the box" in " "prov[ing]' the truth of logic"). I discuss Judge Posner's observation in Winter, supra note 26, at 1151 nn.142-143.

112. Interestingly, the word "category" is derived from social experience. It derives from the Greek kata agora, which means to speak before the public assembly and refers to a public accusation or affirmation. The Random House Dictionary of THE ENGLish LanGUAGE, supra note 28 , at 327 . A hint of this original sense lingers in the modern usage of "categorical" to mean without exception or unqualified, as in "a categorical denial."

113. See text accompanying notes $\mathbf{3 7 - 3 8}$ supra.

114. "Fish will get you every time-as long, of course, as you allow him that crucial move: the establishment of the inside/outside distinction." Schlag, supra note 24, at 55. added).

115. Consequences, in Doing What Comes Naturally, supra note 2, at 324 (emphasis

116. Id. at 319 (emphasis changed from original). added).

117. Fish v. Fiss, in Doing What Comes Naturally, supra note 2, at 123 (emphasis 
so " 'deeply inside' a context" that theory, rules, and law are all impossible. ${ }^{118}$ And it is impossible to expose our constructs because there is no "position outside belief" from which to do so. ${ }^{119}$ With the abundance of all these containers, it is no wonder that Fish has always and already achieved closure.

Fish, moreover, is very partial about his metaphors. He regularly invokes the set of related metaphors: IDEAS ARE OBJECTS, UNDERSTANDING IS GRASPING, and THE MIND IS A CONTAINER. But his strategy is to make the reader aware that these are metaphors. Thus, he starts Dennis Martinez by telling us that ideas are not objects, that the mind is not a container and, thus, that theory is not something a person "could first grasp (in almost the physical sense of holding it in his hand or in some appropriate corner of his mind) and then consult."120 He invokes these metaphors again when he introduces his critical distinction between theory and belief. "Theories are something you can have-you can wield them and hold them at a distance ...."121 Beliefs, on the other hand, "are not what you think about but what you think with, and it is within the space provided by their articulations that mental activity-including the activity of theorizing-goes on." ${ }^{22}$ In this last statement, Fish has recast the MIND IS A CONTAINER metaphor in an interesting way. He has transposed "belief" for "mind," and (in a truly pragmatist move) "mental activity" for "ideas." Thus, BELIEF IS A CONTAINER within which mental activity can occur.

But there are a few peculiarities about Fish's container, this "space of belief." First, it is always already full. Thus, theory and critical selfconsciousness are impossible because "reflection requires a space in which it can occur, and ... the space of reflection cannot already be occupied by what are to be its objects." 123 Second, the container has very firm, hard edges. ${ }^{124}$ In Fish's arguments, "practice becomes a bounded form of life from which escape can only be envisioned by a transcendental consciousness." 125 This brings us to the third peculiarity: Fish's

118. Id. at 126 (emphasis added).

119. Consequences, in Doing What Comes Naturally, supra note 2, at 331 (emphasis added). Although Fish uses the singular here-"belief," I understand him to be using the term metonymically to refer to the entire belief system that characterizes an interpretive community. Thus, when I use the term in its singular form it should be understood the same way.

120. Dennis Martinez, in Doing What Comes Naturally, supra note 2, at 372 (emphasis added). added).

121. Consequences, in Doing What Comes Naturally, supra note 2, at 326 (emphasis

122. Id. (emphasis added).

123. Critical Self-Consciousness, in Doing What Comes Naturally, supra note 2, at 455 (emphasis added).

124. Thus, Fish warns that "one's beliefs do not relax their hold," id. at 467, and that we have no where to go but to "the (equally frozen) grip of another," id. at 457. Here, Fish has personified the container (going back, strangely enough, to its cognitive source) and placed us inside as the objects. See text following note 122 supra.

125. Drucilla Cornell, "Convention" and Critique, 7 Cardozo L. Rev. 679, 686 (1986); see also id. at 690 ("A form of life is not a straitjacket that binds our thoughts ...."). 
container is flat; it is a two-dimensional box. Because "the "prevailing realm of purposes' covers the field, ... reflection can never get off the ground." 126 (How strange that my claim that Fish's arguments are "flat and unpersuasive" should turn out to be correct in such a literal way.)

Now how did the container get to be this way? Fish constructed it that way, that's how. And that is the point: Fish's interpretive constructs are not descriptions of a "reality" about the nature of practice or interpretive communities. In Fish's own words, it would be "misleading [to] assume[] that the distinction between outside and inside is empirical and absolute, whereas in fact it is an interpretive distinction." 127 These interpretive constructs are the common cognitive tools by which we "have" a conventional world. But Fish, it turns out, is extremely insistent about his use of these constructs; he prefers his to anyone else's.

Indeed, that is the modus operandi of Fish's argument in Dennis Martinez. He castigates everyone for using IDEAS ARE OBJECTS and its related set of metaphors. To Kelman, for example, he is unabashed in declaring that "you can't choose your interpretive constructs, [and] neither can you know them (in the sense of holding them in your hand for inspection)." 128 But he then does just that and asserts the container schema (or faults his targets for not employing it). He objects, for example, that Dworkin "sees the weight of practice-that is, of its history-not as something the agent thinks within, but as something the agent thinks with."129 According to Fish, Dworkin must be wrong because practice is a container in which the judge is situated, not an object that she can inspect from the outside. "To think within a practice is to have one's very perception and sense of possible and appropriate action issue 'naturally'-without further reflection-from one's position as a deeply situated agent."130 (But, then, how does the decision "issue" from that "position"? Where does it go? Don't we have to be in the box too in order to understand it?) And, in his argument with Moore, he observes that a set of assumptions is not something a judge can consult; "rather, it is what he sees with, or more precisely, it is within it that he sees."131

But how or why is this "more precise"? Either because practice-or history or belief or interpretive community- "really" is a container or only because Fish has conceptualized it that way. But how can he insist on that highly conventional construct and deny Dworkin, Moore and Fiss theirs? Fish might try the old reverse on us here and argue that the fact that he and his opponents all conceptualize with and insist upon

126. Critical Self-Consciousness, in Dolnc What Comes Naturally, supra note 2 , at 455 (emphasis added).

127. Change, in Doing What Comes Naturally, supra note 2, at 148.

128. Dennis Martinez, in Dorng What Comes Naturally, supta note 2, at 394 (discussed in text accompanying note 23 supra) (emphasis added).

129. Id. at 386 (emphasis changed from original).

130. Id. at $386-87$ (emphasis changed from original).

131. Id. at 382 (emphasis added). 
these highly conventional metaphors only shows that we are all equally enmeshed in our cognitive/interpretive constructs. But-now wait just a minute-why are his any better? And why can't we come up with new constructs? Why not say that "[t]he boundaries of our form of life ebb and flow like the sea; it is a sea upon which we are adrift"?132 Why not, indeed.

We have now completed the argument started in the previous subsection. First, I showed that Fish's argument against theory is supported by his wholesale adoption of the objectivist model of rationality. I argued that this adoption of the objectivist model was in no sense necessary, and demonstrated an alternative, nonobjectivist model of rationality that better describes how humans reason. Finally, I showed that Fish's logic is itself metaphorically constructed; that his entire argument depends upon privileging the logic of the container schema. But, if he gives up the objectivist claim to represent things "as they really are," he cannot claim that his use of this particular cognitive construct is the only way these epistemological issues can be constructed. And, of course it isn't. Once we make room for the capacity of imagination (adding "height" to our container), we discover that the world can be constituted in more than one way.

But note that a curious thing just happened: We got self-reflective. That's right: self-reflective. In other words, we used our capacity for critical self-reflection to expose our interpretive constructs and to transform them. In fact, that is what we have been doing throughout this section-disproving Fish at the level of his argument and, at the same time, doing "theory" (with a small-t) by opening up the constructs that underlie his claim. And, in the process, undermining it.

One final point about situatedness. What is situated is an embodied human with a cognitive capacity. What humans are situated "in" is not some reified entity that looks like a box or container. Rather, we are situated in a real physical and social environment that is always in flux and always contingent. We constantly use our imaginative capacities to recast what we find and reconstruct our context in a variety of ways. What Fish's account lacks-and what defeats it-is imagination. To that point we now turn.

\section{Theory, Change, and the Role of Imagination}

It is my contention that one cannot have an account of meaning, rationality, intellectual change, law, morality, or any other human phenomenon without a concept of imagination and an understanding of its central role in the interaction between the human organism and the environment. I elaborate this claim in the subsections that follow. In

132. Cornell, supra note 125 , at 682 . Personally, I am quite partial to oceanic metaphors. See Winter, supra note 95, at 1479, 1492-93, 1512, 1515-16. One could see, however, why Fish might not be. 
the first, I examine Fish's account of change. I show that Fish's account cannot accommodate the phenomenon of intellectual change without undermining the integrity of the interpretive community construct. In the second, I contrast Fish's account with Alasdair MacIntyre's description of change and development in intellectual traditions. ${ }^{133}$ Two features distinguish MacIntyre's more nuanced account from Fish's rigidly bounded account of change within an interpretive community: first, a recognition of the pivotal role of imagination, and second, an interactive concept of mind. I advance this richer account in the third subsection, where I return to Fish's own arguments to demonstrate the essential role of human imagination throughout the entire domain of change. In the final subsection, I show that the resulting theory of change is relevant not only to the practice of law, but also to the predicament in which the legal academy currently finds itself.

\section{A. Accidents Will Happen}

Fish is aware that his particular conception of situatedness leads to "the complaint that an interpretive community, enclosed in the armor of its own totalizing assumptions, is impervious to change."134 In Fish's account, the problem is relatively straightforward and points to its own solution. The premise-which he identifies as shared by Thomas Kuhn, Nelson Goodman, Richard Rorty, and Stanley Fish-is that it is only within one's paradigms, frames of reference, language, or interpretive accounts that one can have a world at all. 135 But this "make[s] a problem out of change; for it is no longer possible to see change as occurring when the world or a piece of the world forces us to revise or correct our description of it."136 This problem has two parts, reflecting both sides of the traditional subject/object dichotomy. On one hand, it is hard to know "what changes if the world and its objects are not independent of the characterizations we make of them." 137 On the other hand, it is hard to understand what causes change if the situated agent can only perceive what coheres with the beliefs that are already in place. ${ }^{138}$

We know, of course, that change occurs. If it doesn't come from the "outside," then it follows (at least within the regime of $P$ or $\sim P$ ) that

133. Alasdair MacIntyre, Whose Justice? Which RationaltTy? 354-65 (1988). MacIntyre's account is heavily influenced by Thomas Kuhn's classic account of scientific change. T. Kunn, Scientific Revolutions, supra note 44. Although MacIntyre does not cite or discuss Kuhn, the influence will be apparent as we proceed.

134. Change, in Doing What Comes Naturally, supra note 2, at 142.

135. Id. at 143-44. The references are to N. Goodman, supra note 101, at 2-3 (quoted supra note 101); T. KuHN, ScIENTIFIC Revolutions, supra note 44, at 113; RICHARd RORTY, Introduction: Pragmatism and Philosophy, in ConsequenCes of Pragmatrsm, supra note 59, at xix; and, more generally, to S. FISH, supra note 19.

136. Change, in Doing What Comes Naturally, supra note 2, at 144.

137. Id. at 144 (emphasis in original).

138. Id. at $144-45$. 
the impetus for change is always and already "inside." The interpretive community must be structured in such a way that it authorizes and enables change.

[A]n interpretive community . . . is an engine of change because its assumptions are not a mechanism for shutting out the world but for organizing it .... The community, in other words, is always engaged in ... the work of transforming the landscape into material for its own project; but that project is then itself transformed by the very work it does. ${ }^{139}$

Fish uses a familiar experience to illustrate this. We may be reading something in another discipline "or in no 'discipline' whatsoever" and suddenly come to realize that it calls into question a professional view previously held. How can this be? The answer, of course, is that this "something would not have been noticed at all (at least not in this way) if there had not been already in place, as part of the community's conception of itself, the assumption of a relationship between it and some neighboring body of knowledge."140 Once "inside," however, this new knowledge becomes just another part of the "assemblage of related beliefs any one of which can exert pressure on any other in a motion that can lead to a self-transformation." 141

This is plausible, of course, and does account for many of these experiences. But not all. It may be that, as a law professor, one tends to notice only what the legal community recognizes as related. But I suspect that Joseph Vining's experience is the more typical:

I was pulled by my children to watch a fascinating television program on the octopus. Suddenly I saw how like the octopus the legal mind is when constructing cases. I said to a colleague that this showed how relevant everything was to law-one could watch a film on octopuses with profit, indeed should watch it. "Down that road lies disaster," he replied. "One will end by reading poetry under a palm tree."142

I mean, since when have legal scholars counted television and movies as a "neighboring body of knowledge," 143 let alone a respectable one? Perhaps we can explain the few who do advert to such sources ${ }^{144}$ as operating under the influence of the law and literature trend. In that sense, we can explain the anomalous forays into popular culture by an internal development within the legal academy. But, as Fish himself

139. Id. at 150 .

140. Id. at 147 .

141. Id. at 146 .

142. Joseph Vining, Legal Identrty $94 \mathrm{n} . *$ (1978).

143. Change, in Doing What Comes Naturaly, supra note 2, at 147.

144. See, e.g., Winter, supra note 2, at 2277-79 (invoking story from the situation comedy “Taxi"); Robert Eli Rosen, Ethical Soap: L.A. Law and the Privileging of Character, 43 U. MramI L. Rev. 1229 (1989); Jeffrey L. Harrison \& Amy B. Mashburn, Jean-Luc Godard and Critical Legal Studies (Because We Need the Eggs), 87 Mich. L. Rev. 1924 (1989); Milner S. Ball, Moral Pluralism, the Tardis, and Rattlesnakes, 56 TENN. L. REv. 13 (1988) (BBC series Doctor Who); Allan C. Hutchinson, Indiana Dworkin and Law's Empire, 96 YALE L.J. 637 (1987), reprinted in AllaN C. Hutchinson, DWelling on the Threshold 57 (1988). 
has observed, the law and literature trend can itself be attributed to an outside contingency: "marketplace conditions in the humanities [which brought] it (by way of disgruntled Ph.D.'s) to the law."145

Fish's problem here is with the totalizing strength of the interpretive community construct. Although he does not deny the existence of the world "outside," Fish nevertheless asserts that the shape of everything on the "outside" is already determined by the assumptions on the "inside." "[T] $]$ he objects we have are all objects that appear to us in the context of some practice, of work done by an interpretive community,"146 so it is always "an interpreted outside."147

[W] hen a community is provoked to change by something outside it, that something will already have been inside, in the sense that the angle of its notice-the angle from which it is related to the community's project even before it is seen-will determine its shape, not after it has been perceived, but as it is perceived. ${ }^{148}$

While this account is an unexceptionable description of how perception and rationality are paradigm-dependent, it merely restates the problem of change. If the new datum is an interpreted datum, and if the shape given by this interpretation coheres with the project, then how can it call the project into question?

Fish suggests two possible answers. Both concern the makeup of an interpretive community. Unfortunately, both prove too much; they solve the particular problem of change but only at the cost of rendering the interpretive community construct vacuous and self-refuting. This is the obvious problem with the first solution, which Fish spends the most time explaining. An interpretive community "is at once homogeneous with respect to some general sense of purpose and purview, and heterogeneous with respect to the variety of practices it can accommodate."149 Now this is great stuff-interpretive community as intellectual melting pot, so to speak-until we see it in operation. In operation, an interpretive community turns out to be "a set of interlocking assumptions one of which can always be brought into play as a check against the others." 150

The problem is that Fish has just undermined his most important claim: The principal attribute of an interpretive community is that it is "always and already" a constraint on the situated agent. ${ }^{151}$ But, if the

145. Consequences, in Doing What Comes Naturally, supra note 2, at 339. Elsewhere, Fish invokes this very quality of contingency to show that a "theory of change, complete with criteria and predictive formula" is not possible. Change, in Doing What Comes Naturally, supra note 2, at 153 (emphasis in original).

146. Change, in Doing What Comes Naturally, supra note 2, at 153.

147. Id. at 148 (emphasis in original).

148. Id. at 147 (emphasis in original).

149. Id. at 149 .

150. Id at 152 .

151. Fish's adumbrations of this claim are legion, but a fair sampling would include Fish v. Fiss, in Doing What Comes Naturally, supra note 2, at 127 ("Just as rules can be read only 
interpretive community is characterized by heterogeneity and mutually checking assumptions, the situated agent will always have an optionworse yet, a set of potentially contradictory options equally authorized by his or her interpretive community. Instead of "always and already" constrained, the situated agent turns out to be "always and already" free (in a constrained sort of way, of course). What Fish has done, you will note, is simply to recreate the critical legal studies claim that legal discourse is indeterminate: Either the interpretive community is beset by internal contradictions, ${ }^{152}$ or its project is framed at a level of generality so high that contradictory positions are equally authorized. ${ }^{153}$ In other words, if an interpretive community is all things to all people, then it is something that-as Fish says of "theory"-cannot have any consequences.

The second problem is more complex, but it too undermines Fish's strong claim that the interpretive community authorizes all meaning and constrains all situated agents. An interpretive community is able to authorize change because:

Even though the mind is informed by assumptions that limit what it can even notice, among those is the assumption that one's assumptions are subject to challenge and possible revision under certain circumstances and according to certain procedures .... [T] he mind (and, by extension, the community) is an engine of change, an ongoing project whose operations are at once constrained and the means by which those same constraints can be altered. ${ }^{154}$

This account has a powerful intuitive appeal. Any belief system has some such set of meta-procedures or "protocol" for change. This addition to the account of interpretive communities is also, in my view, a significant step forward. By incorporating a protocol for change as part of his account of interpretive communities, Fish has finally broken out

in the context of the practice they supposedly order, so are those who have learned to read them constrained by the assumptions and categories of understanding embodied in that same practice."); Change, in Doing What Comes NATURAlly, supra note 2, at 156 ("[S]ince the change that is inevitable is also orderly-constrained by evidentiary procedures and tacit understandings that at once enable change and are changed by what they enable-license and willful irresponsibility are never possibilities."); Dennis Martinez, in DoIng What Comes NatuRALLY, supra note 2, at 386 ("an agent so embedded would not need anything external to what he already carried within him as a stimulus or guide to right-that is, responsible-action").

152. See, e.g., Mark Kelman, A Guide to Critical Legal Studies 13 (1987) (CLS scholars claim that the legal system is committed to contradictory norms); Duncan Kennedy, Form and Substance in Private Law Adjudication, 89 HARv. L. REv. 1685, 1766-76 (1976) (two conflicting fundamental premises, altruism and individualism, organize legal discourse); Duncan Kennedy, The Structure of Blackstone's Commentaries, 28 BuffaLo L. REv. 205, 211-19, 354-60 (1979) (doctrinal structures exhibit "the fundamental contradiction" between need for others and fear of annihilation); Mark Tushnet, Following the Rules Laid Down: A Critique of Interpretivism and Neutral Principles, 96 HARv. L. REv. 781, 810-18 (1983) (any judicial decision can be shown to be both consistent and inconsistent with precedent; decisions can be said to embody many different principles).

153. See, e.g., Joseph William Singer, The Player and the Cards: Nihilism and Legal Theory, 94 YALE L.J. 1, 16 (1984); Tushnet, supra note 152, at 790-91.

154. Change, in Doing What Comes Naturally, supra note 2, at 146. 
of stasis and recognized the dynamic nature of human processes (although not dynamic enough, as we shall see). Unfortunately for Fish, this very dynamism will yield a "Catch-22" for his version of the antifoundationalist position. ${ }^{155}$

The problem appears as soon as one asks why an interpretive community might develop a protocol for change. For most of us, the obvious answer would be that the experience of the community had previously caused change and that, in response, it developed criteria and procedures for recognizing and incorporating such changes. But this creates a problem for Fish. "[S]ince descriptions of the world are all we have,"156 Fish's interpretive community could never have experienced a first impetus for change. The crucial point is that Fish has no concept of the world separate from its description as part of an interpretive account, and that account limits what can be perceived. It follows that the world and its objects cannot "force[] us to revise or correct our description of it."157 If everything always appears consistent with what the community believes, why would it bother to develop a protocol for change? Change might still occur as a result of contingencies that affect the composition of the interpretive community, but that experience is not likely to give rise to the need to develop protocols.

To put it succinctly, Fish has no concept of anomaly. ${ }^{158}$ A pivotal element in Thomas Kuhn's account of scientific change, anomalies are "[p]roduced inadvertently by a game played under one set of rules[;] their assimilation requires the elaboration of another set."159 In Kuhn's account, an anomaly is an experimental result or accidental discovery that cannot be explained by-or that violates the expectations of-the reigning paradigm. It is not, however, the discovery of a new, objective "truth." Quite the contrary. Kuhn suggests that the power of a paradigm is such that the anomalous data usually goes unrecognized for some time:

[N]ovelty emerges only with difficulty, manifested by resistance, against a background provided by expectation. Initially, only the anticipated and usual are experienced .... Further acquaintance, however, does result in awareness of something wrong .... That awareness of anomaly opens a period in which conceptual categories are adjusted until the initially anomalous has become the anticipated. ${ }^{160}$

Thus, like Fish, Kuhn recognizes that preexisting assumptions deter-

155. A "Catch-22" takes the form: "If $A$, then $B$; but if $B$, then $\sim A$." The term derives from the modern novel of the same name. JOSEPH HELLER, CaTCH-22 46 (1955). It is, however, as old as "the liar's paradox." For a thorough discussion, complete with doctrinal examples, see Schlag, supra note 37, at 944-52.

156. Change, in Doing What Comes Naturally, supra note 2, at 144.

157. Id.

158. I am indebted to David Caploe for this insight.

159. T. KUHN, SCIENTIFIC Revolutions, supra note 44, at 52.

160. Id. at 64 . 
mine the shape of objects on the "outside." But, unlike Fish's much stronger version, Kuhn recognizes that there are objects "out there" in the world that, from time to time, just don't conform to expectations. ${ }^{161}$ When these anomalies are finally recognized, they don't come with their own theory-independent descriptions. Rather, a new description is developed that accommodates the new data in terms of a new paradigm.

As before, Fish is undone by his commitment to closure. The problem inheres in the all-or-nothing nature of Fish's interpretive community construct. For Fish, nothing can exist outside a community's interpretive accounts. For Kuhn, on the other hand, anomalies slowly intrude upon and then transform the work of interpretive communities. In other words, the "outside" can prompt theory change that is not in any meaningful sense constrained by the "inside." To the contrary, the anomalies can be an impetus for a new "inside."

\section{B. Changes}

Alasdair MacIntyre's historical study of change and development in intellectual traditions extends Kuhn's concept of anomaly beyond the physical sciences. ${ }^{162}$ In its first stage, MacIntyre explains, every tradition starts "from some condition of pure historical contingency, from the beliefs, institutions, and practices of some particular community ...."163 The community will have its authoritative texts and voices, as well as a relatively stable set of norms. Despite the stability of these norms, the community will always be in a state of change because the meaning of the stated norms will develop as they are applied to changing contingencies. ${ }^{164}$

The second stage is characterized by the development of anomalies.

161. Kuhn, Reflections, supra note 44, at 263 ("[N]ature cannot be forced into an arbitrary set of conceptual boxes. ... [N] [ature will not indefinitely be confined in any set which scientists have constructed so far."). This statement and the one in the text may seem scandalous to hard-core anti-objectivists. But it is not a suggestion that there are theory-independent facts. The emergence of an anomaly is not an event independent of previous conceptualizations: "Anomaly appears only against the background provided by the paradigm." T. KUHN, SCIENTIFIC REvolutions, supra note 44 , at 65 . Its resolution, moreover, is not a product of simple confrontation with a theory-independent "reality." Rather, "[t]he decision to reject one paradigm is always simultaneously the decision to accept another, and the judgment leading to that decision involves the comparison of both paradigms with nature and with each other." Id. at 77 (emphasis in original).

162. A. MACINTYRE, supra note 133, at 354-65. In the postscript to the second edition, Kuhn expresses some puzzlement over the application of his theory beyond science. He thinks that his account of scientific change makes science more like other disciplines, but that science is still significantly different from other disciplines. T. KuHN, ScIENTIFIC RevoluTIONS, supra note 44, at 208-09. My own sense is that the legal community, especially the legal academy, bears significant parallels to the scientific community as Kuhn describes it. Both rely on standardized textbooks for initiation into the profession; both enjoy substantial insulation from the laity; both concern day-to-day puzzle solving; and both display quite similar internal communal structure. See id. at 163-68, 177-78.

163. A. MACINTYRE, supra note 133 , at 354 .

164. See id. Similarly, Fish gives an example in which a stable norm operates unpredict- 
Incoherencies may develop as norms are elaborated in application. ${ }^{165}$ Disparate and conflicting interpretations may destabilize the authority of the canon. New situations may engender questions that reveal the inadequacy of the existing system of belief. Exposure to other traditions or cultures "may open up new alternative possibilities and require more than the existing means of evaluation are able to provide." 166

What happens in the third stage depends not only on the existing assumptions and beliefs of community members, "but also upon their inventiveness."167 Some set of reevaluations and reformulations will occur; they will be expressed as new beliefs and embodied in new social practices. At this juncture, community members are in a position to contrast the new beliefs with the old. The discrepancy revealed will make the former beliefs seem false relative to the reconstituted system of belief. ${ }^{168}$ This process constitutes the crucial stage of self-reflection at which a tradition will formalize and institutionalize "its methods of enquiry," 169 which will include what I referred to above as protocols for change.

One further aspect of MacIntyre's account is crucially relevant to our concerns, if only because it sounds so much like the state of the legal academy today:

At any point it may happen to any tradition-constituted enquiry that by its own standards of progress it ceases to make progress. Its hitherto trusted methods of enquiry have become sterile. Conflicts over rival answers to key questions can no longer be settled rationally. Moreover, it may indeed happen that the use of the methods of enquiry and of the forms of argument, by means of which rational progress had been achieved so far, begins to have the effect of increasingly disclosing new inadequacies, hitherto unrecognized incoherences, and new problems for ... which there seem to be insufficient or no resources within the established fabric of belief. ${ }^{170}$

This stage of "epistemological crisis" presages the establishment of a new paradigm. ${ }^{171}$

ably because "it is an entirely flexible instrument for organizing contingent experience." Change, in Doing What Comes Naturally, supra note 2, at 150-51.

165. Kuhn reports that something similar happened to Ptolemaic astronomy. As research and observation prompted adjustments to Ptolemy's system, the system increased in complexity without increasing in accuracy; "a discrepancy corrected in one place was likely to show up in another." T. Kunn, SCIENTIFIC Revolutions, supra note 44, at 68.

166. A. MACINTYRE, supra note 133 , at 355 .

167. Id.

168. Id. at 355-56; $c f$. T. KuHN, ScIenTIFIc Revolutions, supra note 44, at 115 ("Looking at the moon, the convert to Copernicanism does not say, 'I used to see a planet, but now I see a satellite.' That locution would imply a sense in which the Ptolemaic system had once been correct. Instead, a convert to the new astronomy says, 'I once took the moon to be (or saw the moon as) a planet, but I was mistaken.'").

169. A. MACINTYRE, supra note 133 , at 358.

170. Id. at 361-62.

171. Compare id. at 361-64 with T. KuHN, SCIEnTific Revolutions, supra note 44, at 6691. MacIntyre's use of the term "epistemological crisis" should not be understood to suggest 
In order to resolve an epistemological crisis without abandoning the tradition altogether, the new paradigm will have to meet three conditions. First, it will have to be a "radically new" or "conceptually enriched scheme" in order to resolve the inadequacies and incoherencies of the previous paradigm. Second, it will have to account for why the old paradigm failed. Third, it will have to fulfill these conditions in a way that "exhibits some fundamental continuity . . . with the shared beliefs [by] which the tradition ... had been defined up to this point."172

This is a tall task, and it requires a solution of a particular kind: Because the new paradigm must solve the very problems that escaped its predecessor, there will be no way to derive it from the paradigm it is to replace. "Imaginative conceptual innovation will have had to occur."173

Another solution seems possible: Adapt a new paradigm from some rival tradition. But note the problem this creates. The rival tradition must be able to do the very things that the tradition-in-crisis cannot, otherwise it will be of little use to the tradition-in-crisis. In that case, the rival tradition must be sufficiently different to present a problem of at least partial incommensurability. At the least, the rival tradition would have to conceptualize the world differently with respect to the anomalies and problems that precipitated the epistemological crisis. In that case, the inquirer will have to be "able to place him or herself imaginatively within the scheme of belief inhabited by those whose allegiance is to the rival tradition, so as to perceive and conceive the natural and social worlds as they perceive and conceive them." 174 Thus, in either event, the successful resolution of an epistemological crisis will depend on an act of the imagination that transports the tradition beyond its previous conceptions. ${ }^{175}$

Now this analysis is very different from Fish's account, in which it is

that the crisis concerns only the technical subject matter of epistemology. Rather, the suggestion is that, with the breakdown of the tradition's paradigms, all inquiry and knowledge are put in question.

172. A. MACINTYRE, supra note 133, at 362. MacIntyre's first and third conditions are parallel to Kuhn's criteria. T. KuHN, ScIENTIFIc Revolutions, supra note 44, at 169.

173. A. MacINTYRE, supra note 133, at 362. Similarly, Kuhn stresses the nonlinear, noncumulative quality of a paradigm shift.

The transition from a paradigm in crisis to a new one ... is far from a cumulative process, one achieved by an articulation or extension of the old paradigm. Rather it is a reconstruction of the field from new fundamentals, a reconstruction that changes some of the field's most elementary theoretical generalizations as well as many of its paradigm methods and applications.

T. Kunn, Scientific Revolutions, supra note 44, at 84-85.

174. A. MAcINTYRE, supra note 133, at 394-95; see also id. at 364-65. MacIntyre observes that this "secondary mode" of understanding the concepts of another culture is a work of "conceptual imagination [that] differs in important ways from possessing the concepts which are genuinely one's own." Id. at 395.

175. See T. Kunn, Scientific Revolutions, supra note 44 , at 97 ("Obviously, then, there must be a conflict between the paradigm that discloses anomaly and the one that later renders the anomaly lawlike."). 
the interpretive community "whose warranting assumptions delimit what can be seen and therefore what can be described . . ."176 In MacIntyre's account, both the impetus for change and its successful negotiation arise in the imaginative interaction between the community and its environment. In Fish's version, change can only occur as a result of something that has already enabled it from within.

This difference between Fish's and MacIntyre's accounts of change reflects an important underlying difference in their conceptions of mind. For Fish, the mind is both an extension of and rigidly bounded by the system of beliefs in which it is situated; "it is only within them that ... [a situated agent] can think about alternative courses of action or, indeed, think at all."177 For Fish, BELIEF IS A CONTAINER within which mental activity can occur. ${ }^{178}$ MacIntyre, however, has a very different conception of mind.

It is rather of mind as activity, of mind as engaging with the natural and social world in such activities as identification, reidentification, collecting, separating, classifying, and naming and all this by touching, grasping, pointing, breaking down, building up, calling to, answering to, and so on.... The mind, being informed as a result of its engagement with objects, is informed by both images which are and are not adequatefor the mind's purposes-re-presentations of particular objects or sorts of objects ....179

This account, like Kuhn's, accepts the nonobjectivist insight that we cannot know the world apart from our descriptions of it. 180 But it understands reason as a faculty that occurs in an embodied social creature situated in and interacting with a real physical and social environment.

MacIntyre's account of mind and rationality is, thus, similar in important ways to the approach to mind developed in the previous sub-

176. Change, in Doing What Comes Naturally, supra note 2, at 152. For Fish, the "problem" of change occurs because of the way in which he privileges what is, in effect, one side of the traditional subject/object dichotomy. See text accompanying notes 135-137 supra. Strictly speaking, Fish has no concept of the "subject"; he "conceives of persons not as free agents, but as extensions of interpretive communities." Change, in DoING What ComEs NatuRALLY, supra note 2, at 152 (emphasis added). But, in effect, he treats the community as a subject writ large, and all meaning is constituted by this community. Thus, for example, he transposes "system of belief" for "mind" in his use of the MIND Is A CONTAINER metaphor and argues that all mental activity must take place within the space of these beliefs. See text accompanying notes 121-123 supra.

Just as Pierre Schlag has shown that the emperor has no clothes, see note 30 supra, Drucilla Cornell has demonstrated that he has no subjects. Indeed, Fish's complete effacement of the subject is another one of the problems with his interpretive community construct. See Cornell, supra note 125, at 689-91.

177. Consequences, in Doing What Comes Naturally, supra note 2, at 323.

178. Id. at 326 (" [I]t is within the space provided by their articulations that mental activity-including the activity of theorizing-goes on.").

179. A. MACINTYRE, supra note 133, at 356-57 (emphasis added).

180. See, e.g., T. KuHn, ScIENTIFIC Revolutions, supra note 44, at 113 ("[O]ne suspect[s] that something like a paradigm is prerequisite to perception itself. What a man sees depends both upon what he looks at and also upon what his previous visual-conceptual experience has taught him to see."). 
sections. ${ }^{181}$ Both recognize our imaginative capacity to recast what we find and reconstruct our context by reconceptualization. I demonstrate the aptness of this account in the next subsection.

\section{Imagine}

If Fish's bounded account of change is true at all, it must certainly be true of the practice of normal science-that is, work undertaken within a single interpretive community. Yet, even here, Fish's account of practice fails to accommodate the vital role of human imagination. Indeed, on the crucial question, Fish's version has it exactly backwards. As before, I will use Fish's own argument to make my point.

In Dennis Martinez, Fish retells a story from industrial research and development that is intended to reinforce his account that a situated agent embedded in a practice "does" that practice first and develops theories only later. The story comes from a paper on generative metaphor by Donald Schön. ${ }^{182}$ It concerns a group of researchers who were experimenting with a new paintbrush made of synthetic bristles. The problem was that the synthetic brush didn't work very well; the paint went on "gloppy" instead of smooth. Finally, one of the researchers said, "You know, a paintbrush is a kind of pump!" This insight led the researchers to focus on the spaces between the bristles and the way in which the brush forced the paint to flow through these channels. This, in turn, led them to a solution to the gloppiness problem. Subsequently, the researchers articulated a "theory" of "pumpoids" to account for the range of hydraulic phenomena characteristic of paintbrushes, pumps, mops, and washcloths. ${ }^{183}$

The difficulty with Fish's account is that he seems to miss or elide most of what is important about this example of technological change. In Fish's view of the cognitive process, you will recall, all perception is paradigm-dependent in the sense that, when some previously unrelated object like the pump is first noticed, "the angle from which it is related to the community's project even before it is seen ... will determine its shape ... as it is perceived." 184 But in the "pumpoid" story, something quite different is happening. The paintbrush project prompts the researcher to think about pumps, but that project does not determine the shape of the pump as it is first perceived. Indeed, exactly the opposite

181. See text accompanying notes 95-112 \& 132-133 supra. See also T. KuHN, ScIENTIFIC Revolutions, supra note 44 , at 125 (referring to "the world determined jointly by nature and by the paradigms upon which ... [one] ha[s] been raised").

182. Schön, Generative Metaphor: A Perspective on Problem-Setting in Social Policy, in MetaPHOR AND THOUGHT, supra note 105, at 254.

183. Id. at 257-60, recounted in Dennis Martinez, in Doing What Comes Naturally, supra note 2 , at $374-75$.

184. Change, in Doing What Comes Naturaldy, supra note 2, at 147 (emphasis in original). But cf. T. KuhN, Scientific Revolutions, supra note 44, at 97 ("Paradigms provide all phenomena except anomalies with a theory-determined place in the scientist's field of vision.") (emphasis added). 
is the case: "When one of the researchers said, 'You know, a paintbrush is a kind of pump!' he was himself thinking of the paintbrush as a pump, seeing it as a pump, and he was inviting the other researchers to do likewise."185 This imaginative insight "led him and the other researchers to notice new features of the brush and of the painting process." 186 In other words, it was the new object (the pump) that shaped the way in which the researchers perceived the old project (the brush). ${ }^{187}$

There is also the problem of what Fish elides in his version of the "pumpoid" story. Fish reports that:

[I]t would be tempting to conclude "that the researchers mapped their descriptions of 'pump' and 'pumping' onto their initial descriptions of 'paintbrush' and 'painting' '; but this would be incorrect, says Schön, because it would make a groping developmental process into a formal and explicit program. ${ }^{188}$

Well, not quite what Schön says. ${ }^{189}$ "Groping" is Fish's description of the process. Schön's account of how the researchers achieved their breakthrough turns out to be rather more deliberate and rather more complex.

As the researchers explore the paintbrush in the light of the possibility of its being a kind of pump, they focus on new features of the brush (the spaces between the bristles, for example); they regroup and reorder features in relation to one another (perceiving the paint as a liquid that flows through the spaces between bristles); and they rename the new grouping of elements (bristles become the "walls" of "channels")....

[I]t is significant that the participants are involved in a particular concrete situation; at the same time that they are reflecting on the problem, they are experiencing the phenomenon of the problem.... It is as though the effort to map onto one another descriptions which initially resist mapping cause the participants to immerse themselves, in reality or in imagination, in concrete situations which are informationrich. ${ }^{190}$

The key elements that Fish omits from his account of the researchers'

185. Schön, supra note 182 , at 258 .

186. Id.

187. Id. at 259 ("[T] he new putative description already belongs to what is initially perceived as a different, albeit familiar thing . ...").

188. Dennis Martinez, in Doing What Comes Naturazly, supra note 2, at 375 (quoting Schön, supra note 182 , at 259).

189. What Schön actually says is that to conceive that "the researchers mapped their descriptions . . . would be at least partly incorrect." Schön, supra note 182, at 259 (emphasis in original). The difference is striking in two ways. First, Fish totalizes: "partly incorrect" becomes simply "incorrect." Second, Schön's stress on the word "mapped" signals that he is saying only that the process was not mechanical. It is not, as Fish would have it, that the researchers acted as agents deeply embedded in practice "groping" their way to a solution. The critical difference will be immediately clear in the text that follows.

190. Schön, supra note 182 , at 277 . 
efforts are reflection, imagination, and their part in the interaction between situated agents and the environment.

Fish's omissions here are also what undermine his general account of change. For Fish, "descriptions of the world are all we have," 191 and every description is always and already shaped by a preexisting interpretive account. As a result, he has no explanation for how we create new meanings not already shaped by what we believe. If the scientific community previously thought of brushes and pumps as unrelated phenomena, ${ }^{192}$ then they should never even have been able to see the relevance of the pump, let alone reconceptualize the brush in terms of a pump. For Schön, on the other hand, the "pumpoid" story illustrates the power of imagination to create new meanings out of previously unrelated experiences. Schön sees the process at work in the "pumpoid" story as "one of metaphor making, rather than simply of redescribing." 193 "Paintbrush-as-pump was a generative metaphor for the researchers in the sense that it generated new perceptions, explanations, and inventions." 194

The lesson of the "pumpoid" story can be extended. Imagination plays a central role throughout the entire domain of change. Indeed, the imaginative process of metaphoric reasoning often produces the anomaly that prompts change. ${ }^{195}$ The same cognitive process can be observed when a perception or understanding that originates in another intellectual domain prompts reconceptualization within one's own discipline. We have already encountered an example of this in the story told by Vining. The television account of the octopus's defensive behavior gave him new insight into the defenses of the legal mind that structure closely related procedural questions in quite different ways. As a consequence, Vining was led to wonder "why, if the courts can be articulate in the difficult decisions on relief pendente lite, they are not equally articulate when standing and jurisdiction are in issue." 196 So too, it is the imaginative reconceptualization that yields a new paradigm. As MacIntyre argues, imagination plays a central role in the successful negotiation of epistemological crisis in an intellectual tradition.

191. Change, in Dorng What Comes Naturally, supra note 2, at 144.

192. "In fact, no one (including the speaker) did know that [a paintbrush is a kind of pump] until it was hazarded as an observation ...." Dennis Martinez, in Doing What Comes NaturalLy, supra note 2, at 374 .

193. Schön, supra note 182, at 259.

194. Id. (emphasis in original).

195. Kuhn gives the marvelous example of the developments that led Franklin to formulate a new paradigm for electricity. "One of the competing schools of electricians took electricity to be a fluid, and that conception led a number of men to attempt bottling the fluid ...." T. Kunn, ScIentific Revolurions, supra note 44, at 61 . Their attempts led to the invention of the Leyden jar, a device to store electricity. Id. at 61-62. The experiments by which this invention emerged, however, "were also the ones that necessitated the drastic revision of the fluid theory and thus provided the first full paradigm for electricity." Id. at 62 . Today, the device is known as the capacitor or condenser and no longer involves a jar.

196. J. Vining, supra note 142, at 94 (discussed in Winter, supra note 95, at 1512). 
D. Moods for Moderns

We have, so far, enriched Fish's rather limited account by elaborating the role that interaction, imagination, and self-reflection play in producing change at a variety of different stages or levels. In contrasting Fish's explanation of change with MacIntyre's and Kuhn's more complex accounts, we might be tempted simply to conclude that Fish is wrong and the others right. But, in fact, the two accounts agree substantially at what MacIntyre calls the first stage, or what Kuhn calls normal science. ${ }^{197}$ Unfortunately for Fish, however, this partial congruence between his account and those of MacIntyre and Kuhn argues for the relevance of "theory with a small- $t$ " to the processes of change: By combining these accounts, we can develop paradigms that can be helpful in understanding and influencing the directions of social change.

The traditional conception of the common law, for example, conforms to MacIntyre's account of the first stage of an intellectual tradition. The authoritative voices are those of the common law judges, and the canonical texts are found in the body of precedent. Even when these precedents are understood to contain a stable set of legal rules, the law will be in a constant state of change as those rules are applied to changing fact-patterns. ${ }^{198}$ At this stage, legal practice will appear substantially similar to Fish's account of change within a single interpretive community. What will be seen as relevant to the law will be only those disciplines-like econometrics, medicine, psychiatry-that the legal community recognizes as related to its project. Change will be the norm, but it will be change according to the conventional practices and protocols of the profession. Cases will be distinguished, rules restated and extended, and precedents overruled.

But Fish's account has severe limits. However effective the socialization of new judges and lawyers, the conventions of the legal community will inevitably produce anomalies. There will be incoherencies in the doctrines, conflicting interpretations of the cases, and new contingencies that cannot be dealt with adequately under the established rules. Reformulations will occur; normal practice may then resume. But there will also be times of crisis when the anomalies escalate and outstrip reformulations.

An understanding of these complex phenomena will be instrumen-

197. See note 164 supra and accompanying text.

198. Similarly, Karl Llewellyn argued that the degree of change in a legal system will depend on

whether . ... the direction and degree of semantic change in a legal rule (or a verbal symbol used by the rule) keep[s] up with the corresponding change in the real-life situation. ... [I]f the change on the judge's part is keeping up perfectly, neither judge nor layman realizes that any change has occurred. . . .

Karl N. Llewellyn, The Case Law System in America, 88 Colum. L. Rev. 989, 1013 (1988) (P. Gewirtz ed., M. Ansaldi trans.). 
tally useful to advocates interested in effectuating change. Since most legal practice occurs within a framework analogous to Kuhn's normal science, advocates of change must be able to exploit latent tensions and possibilities for change within the existing paradigms of legal practice. Someone in the position of Thurgood Marshall and his associates in 1954, for example, would find it more effective to employ a kind of juridical jujitsu in appealing to conventional assumptions about equality and fairness. ${ }^{199}$ But legal practice is not always so predictably stable. Counsel arguing a commerce clause case in 1937 would have been making a grave error in relying on the assumptions about federalism that had prevailed up to that point.

Fish might object that the advisability of these different strategies is clear only in retrospect. The respective lawyers could only have thought that they were operating in a normal environment because, Fish would claim, that assumption is constitutive of practice. ${ }^{200}$ But I think this is wrong. The lawyer practicing during the later New Deal would (or, at least, should) have been well aware of the burgeoning constitutional crisis. The economic depression, the continuing conflict between the election results and the advance sheets, ${ }^{201}$ and the legal realist assault on the intellectual foundations of the Old Court's formalist jurisprudence ${ }^{202}$ were all indications of a crisis in law that reflective practitioners would not have ignored.

The advantage to be gained from this kind of theory (with a small-t, of course) is the advantage of self-reflective action. For someone who wants to effectuate change, it will be extremely useful to know whether one is operating within a period of normal science or a time of crisis. What the reflective practitioner needs are models of change that can be used to distinguish the two situations. These could be sketched on the basis of the competing accounts of change we have surveyed.

Fish's account of change can be seen as a useful model during periods of normal science. During those periods, perception is highly dependent on the conventional paradigms and assumptions. An

199. Part of this appeal to established values included a sustained effort to educate the Court about the full dimensions of the inequalities faced by blacks within a segregated system 'of education. See Winter, supra note 2, at 2275-76 (discussing the cognitive strategies of the litigation campaign that led to Brown).

Guyora Binder explains the strategy of the civil rights movement in terms of the postWorld War II "culture of conformity .... In this cultural climate, it was not only possible but necessary for black leaders to claim to represent a national consensus rather than a particular group." Guyora Binder, On Critical Legal Studies as Guerrilla Warfare, 76 Geo. L.J. 1, 14-15 (1987). In my view, this is an apt description of the cultural milieu in which the legal efforts of the movement took place. It is consistent with my observation elsewhere that legal meaning is continuous with-in the sense of being grounded in and contingent on-general cultural meaning. See Winter, supra note 26, at 1197; Winter, supra note 2, at 2267-71.

200. See, e.g., Dennis Martinez, in Doing What Comes Naturally, supra note 2, at 386-87 (quoted in text accompanying note 130 supra).

201. See Bruce A. Ackerman, The Storrs Lectures: Discovering the Constitution, 93 YALE L.J. 1013, 1053-57 (1984).

202. See Kennedy, Form and Substance, supra note 152, at 1748-60. 
argument for a new position-for the relevance of new data, for borrowing ideas or approaches from neighboring disciplines, or for other innovations-will be more persuasive if it conforms to some assumption or element already existing within the world-view of one's interpretive community.

During periods of crisis, on the other hand, precisely the opposite will be true. An appeal to the reigning paradigm will, at best, further entrench contradiction and produce increasing anomaly. ${ }^{203}$ Confronted with a new paradigm, an advocate who continues to press the old assumptions can be reduced to stuttering confusion. ${ }^{204}$ At such times, the most useful strategy will be to look outside one's interpretive community for models and schemes that might help reconceptualize the problems that have proven recalcitrant to the old paradigm.

I suggested earlier that the legal academy is experiencing a state of epistemological crisis. If I am right, it would be a mistake to accept Fish's suggestion that change is inevitable, orderly, and "constrained by evidentiary procedures and tacit understandings. . ."205 Indeed, it would be an abdication of responsibility to do so when change could be influenced in more humane and productive directions.

There are several indications that ours is a period of crisis and not normal science. Perhaps the foremost indicium is the continuing preoccupation with the indeterminacy debate. ${ }^{206}$ As Kuhn observes:

When ... an anomaly comes to seem more than just another puzzle of normal science, the transition to crisis and to extraordinary science has begun. The anomaly itself now comes to be more generally recognized as such by the profession. More and more attention is devoted to it by

203. Thus, Kuhn rejects the usefulness of interpretation in times of crisis, arguing that something more is required.

Given a paradigm, interpretation . . . is central to the enterprise that explores it. But that interpretive enterprise ... can only articulate a paradigm, not correct it. Paradigms are not corrigible by normal science at all. Instead, as we have already seen, normal science ultimately leads only to the recognition of anomalies and to crises. And these are terminated, not by deliberation and interpretation, but by a relatively sudden and unstructured event like the ges[t]alt switch. ... No ordinary sense of the term "interpretation" fits these flashes of intuition through which a new paradigm is born. Though such intuitions depend upon the experience, both anomalous and congruent, gained with the old paradigm, they are not logically or piecemeal linked to particular items of that experience as an interpretation would be.

T. KuhN, Scientific Revolutions, supra note 44 , at 122-23.

204. For an account of just such an example during the course of a pivotal Supreme Court argument, see Winter, supra note 95, at 1450-51 (discussing Coleman v. Miller, 307 U.S. 433 (1939)).

205. Change, in Doing What Comes Naturally, supra note 2, at 156.

206. See, e.g., M. KELMAN, supra note 152, at 13; Winter, supra note 26, at 1180-98; Ken Kress, Legal Indeterminacy, 77 CALIF. L. Rev. 283 (1989); Drucilla L. Cornell, Institutionalization of Meaning, Recollective Imagination and the Potential for Transformative Legal Interpretation, $136 \mathrm{U}$. PA. L. REv. 1135, 1196-1212 (1988); Lawrence B. Solum, On the Indeterminacy Crisis: Critiquing Critical Dogma, 54 U. CHI. L. Rev. 462 (1987); Joan C. Williams, Critical Legal Studies: The Death of Transcendence and the Rise of the New Langdells, 62 N.Y.U. L. REv. 429 (1987); John Stick, Can Nihilism be Pragmatic?, 100 HARv. L. Rev. 332 (1986); Singer, supra note 153; Gary Peller, The Metaphysics of American Law, 73 CALIF. L. REv. 1152 (1985). 
more and more of the field's most eminent [people]. ${ }^{207}$

The second and related indicium is the increasing penetration of philosophy in legal theory. Kuhn reports the same phenomenon in times of scientific crisis. ${ }^{208}$ He explains the paradoxical utility of philosophical analysis to the resolution of crisis: Precisely because the full set of rules it seeks will not exist, the search for philosophical assumptions will "be an effective way to weaken the grip of a tradition upon the mind and to suggest the basis for a new one."209

The third indicium is the proliferation and diversity of interdisciplinary borrowings in legal scholarship. "[C]risis simultaneously loosens the stereotypes and provides the incremental data necessary for a fundamental paradigm shift." 210 The increasing variety of previously unorthodox material in current legal scholarship-the turn to literature, to interpretation, to deconstruction, to cognitive theory, to artifacts of popular culture like television, movies or modern $\operatorname{art}^{211}$-is not, as Fish would have it, a product of the existing conventions of the legal academy. To the contrary, it is the surest sign that less and less of the legal academy experiences its conventions as sufficient to the tasks at hand. ${ }^{212}$

The fourth indicium is the proliferation of "schools" or "movements" within the academy that increasingly talk past one another: law and economics, law and literature, conventionalism, originalism, feminism, critical legal studies. These in turn prompt the responses that typify the fifth indicium: the appearance of articles with titles like The Death of the Law ${ }^{213}$ and The Decline of Law as an Autonomous Discipline. ${ }^{214}$ Kuhn summarizes all these developments in his account of crisis and revolution in scientific inquiry: "The proliferation of competing articulations, the willingness to try anything, the expression of explicit discontent, the recourse to philosophy and to debate over fundamentals, all these are symptoms of a transition from normal to extraordinary research."215

If I am right about the current state of legal theory-and the evi-

207. T. Kunn, Scientific Revolutions, supra note 44 , at 82 .

208. Id. at 88 ("It is, I think, particularly in periods of acknowledged crisis that scientists have turned to philosophical analysis as a device for unlocking the riddles of their field.").

209. Id.

210. Id. at 89 .

211. On modern art, see David Luban, Legal Modernism, 84 MICH. L. Rev. 1656 (1986) (comparing critical legal studies to modernism in art).

212. See Winter, supra note 2 , at $2226-28$ (the turn to narrative and to interpretation is a temporary response to the breakdown of previous legal conventions); see also id. at 2256-67 (demonstrating the inadequacies of the "law as narrative" view).

213. Owen M. Fiss, The Death of the Law?, 72 Cornell L. Rev. 1 (1986).

214. Richard A. Posner, The Decline of Law as an Autonomous Discipline: 1962-1987, 100 Harv. L. Rev. 761 (1987); see also Richard A. Posner, Conventionalism: The Key to Law as an Autonomous Discipline?, 38 U. TORONTo L.J. 333 (1988).

215. T. Kunn, ScIENTIFic Revolutions, supra note 44, at 91. 
dence, I submit, continues to mount even as you read this essay ${ }^{216}$ then two questions remain. The first is whether this insight can inform our practice. Fish would argue that, even with this knowledge, we can only continue within our current practices because they are what constitute us as legal academics. But we have seen that Fish's one-dimensional account fails to capture the maverick, adaptive quality of human imagination: It lacks any conception of situated human agents capable of transformative action from within a given context. ${ }^{217}$ Yet even in times of normal science, the actual practice of any field is characterized by imagination, self-reflection, and creativity. A fortiori, Fish's account holds no claim on us now, for it is certainly inadequate in times of crisis.

The second question is how this insight should inform our practice. Here, we can agree with Fish but on different grounds. There can be no formula for change because there can be no formula for imagination. What is needed is an imaginative creativity for which interdisciplinary borrowing is a necessary but not sufficient precondition. The shape of the paradigm that will ultimately emerge cannot be known in advance. ${ }^{218}$ But if we were to listen to Fish and fail to seek it, we would only prolong the period of crisis.

\section{Struated Self-Consciousness}

The question remains whether it is possible to practice meaningful, reflective self-consciousness. Fish frequently proclaims that it is not, that there is nothing to be gained from the knowledge that there are no foundations for one's beliefs. 219

Whatever you take to be the case about a matter will be a function of interpretive constructs you have not chosen; but the fact that you have now heard the story and believe it doesn't put you in any better position either to choose your interpretive constructs or to neutralize the effects

216. Since writing these lines, sightings of transition and paradigm shift have become increasingly frequent. See, e.g., Laurence H. Tribe, The Curvature of Constitutional Space: What Lawyers Can Learn from Modern Physics, 103 HARv. L. REv. 1, 23-38 (1989); Erwin Chemerinsky, The Sufreme Court, 1988 Term-Foreword: The Vanishing Constitution, 103 HARv. L. REv. 43, 98103 (1989); Philip Bobbitt, Is Law Politics?, 41 Sran. L. Rev. 1233, 1310-12 (1989); Gary Minda, The Jurisprudential Movements of the 1980s, 50 OHIo Sr. L.J. 599, 659-62 (1989).

217. Cf. M. Merleau-Ponty, supra note 84 , at 455 ("The choice which we make of our life is always based on a certain givenness. My freedom can draw life away from its spontaneous course, but only by a series of unobtrusive deflections which necessitate first of all following its course-not by any absolute creation.").

218. In previous work, I have sketched some preliminary arguments for the value of emerging cognitive theory as a signpost to a reconceptualized practice of law. See Winter, supra note 26, at 1113-14; Winter, supra note 2, at 2261-69.

219. See, e.g., Dennis Martinez, in Doing What Comes Naturally, supra note 2, at 394 (quoted at text accompanying note 23 supra); Anti-Professionalism, in DoIng What Comes NatuRALLY, supra note 2, at 246 ("It is thus a condition of human life always to be operating as an extension of beliefs and assumptions that are historically contingent, and yet to be holding those beliefs and assumptions with an absoluteness that is the necessary consequence of the absoluteness with which they hold-inform, shape, constitute-us."). 
of those you still will not have chosen. 220

Indeed, as we have seen, he goes further and claims "that one cannot achieve a distance on one's beliefs."221 Reform, therefore, cannot be aided by self-consciousness because there can be no "option of stepping back from one's beliefs in order to survey or reform them . . .."222

But, as we know from the previous discussion, ${ }^{223}$ Fish's conclusion is buttressed primarily by his choice of metaphors. Yet, as we have seen, there is nothing magical or preordained about the interpretive constructs that he has chosen. Rather, to allow Fish to frame the question in terms of the container schema is to allow him to predetermine the answer. In order to find another answer to the question whether it is possible to achieve "distance" from one's situatedness, we will have to find another way to ask the question.

Fish's strategy is so subtly effective because metaphor is a basic and powerful mode of cognition. By "metaphor" I mean the cognitive process by which we structure our understanding of an abstract domain in terms of a more concretely experienced source domain. In Fish's metaphor, for example, we are led to understand the historical/cultural contingency of our beliefs in terms of the features of physical containers. But in leading us to see the target domain in this way, the metaphor highlights some aspects of our experience at the expense of others. By carefully selecting a single metaphor-always representing belief or practice as a container for mental activity ${ }^{224}$-Fish can shape his point in a powerful, unconscious manner. Thus, if beliefs are the kind of thing we are "within," then it is hard to see how we can achieve any "distance" from them or find another "position" from which to evaluate them. ${ }^{225}$

It is critically important, however, to remain conscious that the metaphor is not the reality. "Mind" and "belief" are not really containers; it is just useful (sometimes) to conceptualize them that way. Because any single conceptualization will fail to capture the many facets of our experience, we typically employ multiple metaphors to conceptualize important or complex phenomena.

Each metaphor takes a slice of reality and compares that cross section with some aspect of our physical experience. ... We use multiple metaphors-repeated cross sections or multiple snapshots-in order to capture more of what we experience and construct a more useful picadded).

220. Dennis Martinez, in Dorng What Comes Naturally, supra note 2, at 395 (emphasis

221. Critical Self-Consciousness, in Doing What Comes Naturally, supra note 2, at 467 (emphasis added) (quoted in full at text accompanying note 53 supra).

222. Id. at 465 (emphasis added).

223. See texts accompanying notes $37-38,113-131$ supra.

224. See texts accompanying notes $113-126,177$ supra.

225. As Fish puts it, "without them (a pun seriously intended) there would be no thinking at all." Dennis Martinez, in Doing What Comes Naturally, supra note 2, at 394. 
ture of the reality around us. 226

Indeed, we have many conventional metaphors for a concept as important but equivocal as "mind."227

One such set of conventional metaphors conceives the mind in terms of visual experience. If KNOWING IS SEEING, then IDEAS ARE LIGHT and THE MIND IS A LIGHT SOURCE. Thus, a person can have a brilliant mind; a student can be very bright; our explanations can shed some light on a challenging case; a good article can illuminate a difficult doctrinal area; we are all heirs of the Enlightenment. This metaphoric understanding is similarly manifested in the conception of thought as reflection and of self-consciousness as a matter of self-reflection. Typically, the unspoken assumption is that the world upon which we reflect is being seen as it "really" is. This is why good ideas are perspicuous or clear and bad ones are opaque or obscure. This is what Fish is presupposing when he argues that "even if one is convinced (as I am) that the world he sees and the values he espouses are constructions, ... that conviction will in no way render that world any less perspicuous . . . ."228

This way of understanding the world treats our conceptualizations as transparent in the sense that they are invisible to us. In this view, our constructions do not interfere with our capacity to apprehend the world "clearly" and "correctly." As long as we suppose such transparency, we will experience our beliefs and perceptions as simply true and "objective." Fish's point about the impossibility of critical self-consciousness is an assertion that our ideas are always transparent to us and "that the context is . . . so deeply assumed, that it is invisible to the observer."229

But Fish's argument cannibalizes itself. If the context is invisible because it is deeply assumed, then to bring that assumption to the surface should be to dispel its fixity and make discernible the contingency of the beliefs it supports. To put it another way, the antifoundationalist insight teaches that our view of the world always depends on our particular conceptual scheme (paradigm, frame of reference, language, or interpretive account). Once we have assimilated that insight, what we have learned is that our view is always and already colored by our conceptual assumptions. We know that what we see is not objective, because our conceptual medium is never transparent. It is only a short step from this realization to the conclusion that critical self-consciousness is possible.

We can illuminate that step if we pause to reflect upon how many "impossible" intellectual moves we actually made in the last few

226. Winter, supra note 95 , at 1492-93. 1189.

227. See, e.g., G. LAKOFF \& M. JohnSon, supra note 105, at 27-28; Winter, supra note 26, at

228. Anti-Professionalism, in Dorng What Comes Naturally, supra note 2, at 245 (emphasis added).

229. Consequences, in Doing What Comes Naturally, supra note 2, at 320-21. 
paragraphs. First, we were self-conscious about Fish's interpretive constructs and how they function in his argument. Second, we surveyed the other constructs that are part of our conventional, socially situated world and chose another. (If Mark Kelman is with us at this moment, he can breathe easy because he has now lived to see what Fish has sworn he never would. ${ }^{230}$ ) Third, we looked at this highly conventional construct and reflected upon the way in which it re-presents our beliefs and perceptions to us as if they were simple, objective truths. Fourth, we got critical about all this self-conscious construction and realized that the world we see in Fish's oeuvre need not be the world we get; it is just one version of it. And, fifth, we accomplished all this by employing a theory: not a theory in the form of a formula or rule "outside" or "above" practice that tells us what to do, but a powerful new paradigm that alerts us to the irreducibly imaginative way in which we cognize and construct our world.

As long as we accept Fish's claim that the only reflective position is an impossibly transcendent position, then we will have to accept his conclusion that critical self-consciousness is inconceivable. But as soon as we recognize that there is more than one way to conceptualize the world, we have somewhere else to go from which we can reflect on our own practices. That somewhere else will not, of course, be unconstructed; it too will be a product of the irreducibly imaginative way in which we construct our world. What we will have escaped, however, is the irresistible "hold" that our beliefs supposedly have on us. ${ }^{231}$ What we will have achieved is a situated self-consciousness: situated not just in our cultural and historical tradition, but also in a real physical and social world that we construct and reconstruct through acts of the imagination.

This achievement is of monumental importance because so much depends on these imaginative and reflective capacities. For situated human agents always shaped by preexisting historical and cultural forces, situated self-consciousness provides the only meaningful sense in which freedom is possible.

Freedom consists not in an unrestricted capacity to define meaning, but in an ability to modulate meanings by transforming elements of the sedimented field of perception. Our freedom comes from our ability to focus our attention on those background decisions, to bring them to the foreground, and to see previously unperceived possibilities for change. ${ }^{232}$

230. Cf. Dennis Martinez, in Dotng What Comes Naturally, supra note 2, at 394 ("Kelman is, of course, right. He has never seen anyone self-consciously select his interpretive constructs; indeed, I would go further and say that no matter how long he lives it is a sight he will never see. ...").

231. Fish frequently personifies "belief" which then holds us in its grip. See notes 124 \& 219 and text accompanying note 53 supra.

232. Kerry H. Whiteside, Merleau-Ponty and the Foundation of an Existential PoLrTICs 68-69 (1988); see note 217 supra and accompanying text. 
Thus, freedom is not "another name for constraint,"233 as Fish would have it. Rather, freedom is another name for reflection, as we might practice it.

What is also at stake is "objectivity."

[T]he belief that there is a God's Eye point of view and that one has access to it (that is, being a hard-and-fast objectivist) virtually precludes objectivity, since it involves a commitment to the belief that there are no alternative ways of conceptualizing that are worth considering. ... $[T]$ o be objective requires one to be a relativist of an appropriate sort.234

Once we give up the notion of the transcendent position (for God, consciousness, or anything else), then "objectivity" becomes a question of transperspectivity. "Impartiality," in turn, is no longer a matter of an aperspectival position, but rather an exercise of the empathetic ability to imagine what a question looks like from more than one side. "Situated self-consciousness," in this view, is a two-part process. First, it involves the capacity to unravel or trace back the strands by which our constructions weave our world together. ${ }^{235}$ Although we may be situ-

233. Critical Self-Consciousness, in Dorng What Comes Naturally, supra note 2, at 459. See text accompanying notes 84-93 supra.

234. G. LAKOFF, supra note 58, at 301-02.

235. The methodology suggested here is something like the process of psychoanalysis. I suspect that this will not be acceptable to Fish, who masterfully dissects Freud's rhetorical strategy. Withholding the Missing Portion: Psychoanalysis and Rhetoric, in DoIng What Comes NatURALLY, supra note 2, at 525-54. Fish's tactic is to apply Freud's theory to Freud's text, which yields some surprising reversals and discloses some powerful insights about Freud.

But, as always, Fish's critique is revealing. The reflexive nature of this critique is too powerful for Fish to escape when it is turned on him. For example, watch what happens when we substitute the words "interpretive community" for "primal scene" and "Fish" for "Freud" in the following paragraph:

In other words, the assumption of the [interpretive community] proves itself by its

effects, by its ability to bring order to an apparently heterogeneous mass of fragments and impressions; once order has been brought, there is nothing it does not comprehend, and therefore no vantage point from which it can be meaningfully challenged .... The investment of work and the yield of that work-certainty, conviction, knowledge-are simply too great to risk losing .... What [Fish] is relying on here is not something newly or additionally persuasive, but on the fact that persuasion has occurred, and that having occurred, we will be unwilling and indeed unable to undo it.

Id. at 546. Now compare the following passage from Schlag:

The concept of interpretive communities is attractive for the simple reason that it leaves the self as the final adjudicator of its own acts without responsibility for the choice. The self cannot choose its interpretive constructs. It is always already within them. But at the same time (and quite conveniently) very little can be known about these interpretive constructs so the self need not feel closeted by an overly determined objectivity. The concept of interpretive communities offers the self a formal closure against the claims of theory, reason, and history. But at the same time, the concept is substantively emply, so that the self can project into "interpretive communities" just about anything it wants.

Schlag, supra note 24 , at 45 (emphasis in original).

For those who are curious, the strategy of this essay has been to emulate Fish and apply Fish's technique to Fish's texts. And, despite the incongruity of the results, the reader should keep in mind that imitation is still the sincerest form of flattery. 
ated in a web of belief, there is nothing that prevents us from making those beliefs translucent and, thus, amenable to reflection. ${ }^{236}$ Nothing, that is, except lack of imagination.

Second, situated self-consciousness involves the ability to imagine how the world might be constructed differently. This may be achieved through the imaginative effort to understand another person's or another culture's construction of the world. ${ }^{237} \mathrm{Or}$, as in the "pumpoid" story, it may involve an act of imagination that uses a known but previously unrelated experience to reconceptualize an existing practice. In either event, situated self-consciousness depends upon an act of the imagination that transports one "beyond" his or her previous conceptions. It is not, as Fish would have it, an attempt to "see through" the historical and cultural forces that dominate one's situation. ${ }^{238}$ Rather, it is a process of first rendering our constructions translucent and then seeing past them to different, perhaps more productive constructions.

To conceptualize situated self-consciousness in this way is to reject all the limiting entailments of the container schema that Fish embraces so avidly. For example, Fish argues that successful persuasion cannot produce "a heightened or raised consciousness" or enable someone to pass "from an unreflective state to a state of new and enlarged awareness." 239 For Fish, "any gain in awareness is simultaneously a loss ... [because a]wareness is not a quantity that can be increased or diminished on an absolute scale; rather, it is a name for what is obvious and perspicuous to us situated as we are within a structure of beliefs."240 But, of course, this is only true because Fish indulges the transparency of his own metaphors. For Fish, the reason that awareness cannot be "heightened" or "expanded" is because he conceptualizes belief as a

236. Compare Merleau-Ponty's description of reflection by situated human agents: It is because we are through and through compounded of relationships with the world that for us the only way to become aware of the fact is to suspend the resultant activity, to refuse it our complicity .... Not because we reject the certainties of common sense and a natural attitude to things-they are, on the contrary, the constant theme of philosophy-but because, being the presupposed basis of any thought, they are taken for granted, and go unnoticed, and because in order to arouse them and bring them to view, we have to suspend for a moment our recognition of them.... Reflection does not withdraw from the world ...; it steps back to watch the forms of transcendence fly up like sparks from a fire; it slackens the intentional threads which attach us to the world and thus brings them to our notice ....

M. Merleau-PonTY, supra note 84 , at xiii.

237. This is exactly what Fish achieves in his superb critique of Posner for not understanding that interpretation is relative to one's assumptions. Fish artfully explains the religious assumptions that make an "anachronistic" reading of Virgil as a Christian allegory "nothing more than the exercise of common sense." Don't Know Much About the Middle Ages: Posner on Law and Literature, in DoIng What Comes Naturaliy, supra note 2, at 294, 299 (essay hereinafter referred to as Don't Know Much About the Middle Ages).

238. Anti-Professionalism, in Doing What Comes Naturally, supra note 2, at 245.

239. Critical Self-Consciousness, in Doing What Comes Naturally, supra note 2, at 462 (emphasis added).

240. Id. (emphasis added). 
flat container with fixed boundaries that is always and already full. ${ }^{241}$ Because Fish conceptualizes mental activity in just that limited, spatial way, any new belief admitted into the container must ipso facto displace some corresponding old belief. ${ }^{242}$

But if we decline to conceptualize the mind (or belief system) as a container, then there is nothing self-evident about this conclusion. If we can see past our practices, then we can add space and expand consciousness. It is not the case that every new conception must displace some older, competing one. Someone who learns a new language does not thereby lose the capacity to speak her native tongue. A person who learns to understand the different world-view of another culture or religion does not ipso facto cease to be who she is. Nor does she become unable to see the world from her own perspective. Rather, by practicing situated self-consciousness, we use our imagination to increase our repertoire of practices and, thus, increase our reflective and empathetic capacities.

Indeed, if Fish were correct, competent lawyering would be an impossibility. I take it as axiomatic that competent advocacy requires one to do more than construct a plausible or persuasive argument for one's own client. It requires the capacity to conceptualize the best arguments for the other side of the case, to see the weaknesses in one's own, and to understand how both sets of arguments will appear to the decisionmaker. ${ }^{243}$ Frequently, the advocate will have to be able to conceive radically different versions of the same facts. Plaintiff swears that the defendant tried to run him over with his car. Did the defendant's transfixed stare bespeak deliberation, inattentiveness, or mental disturbance? In such cases, counsel will have to assess which interpretation will appear "correct" to the decisionmaker and develop strategies to explain, contextualize, or otherwise make persuasive the more dissonant version. Imagine Fish's advocate after he has lost his umpteenth case: "But the facts were on our side!" Competent lawyering is a constant effort at transperspectivity that requires the advocate to entertain and consider many conflicting perspectives and beliefs simultaneously.

241. See text accompanying notes 123-126 supra.

242. Fish supports his totalizing claim with an example in which it is probably true that the new belief would displace the old: "Someone who is now able to see merit as a political or social category is now unable to see merit as intrinsic . ..." Critical Self-Consciousness, in Dorng What Comes Naturally, supra note 2, at 462 (emphasis in original). But it doesn't follow that this must always be the case, as elaborated in the text below.

243. Of course, in doing so, the advocate will typically be using the categories already established within legal practice. But this makes only the point that the advocate is situated. It does not in any way displace the fact that the advocate must still employ self-conscious reflection to conceive the case from many points of view. Nor does it speak to the imaginative potential to recast the standard categories or to invent new ones. Most importantly, it misses entirely the transformative feat performed by the most gifted advocates: the ability to imagine how the decisionmaker will conceive the problem at hand, to identify what it will take to change that conception, and the skill to pull it off. For examples, see Winter, supra note 2, at 2274-79. 
It is important to note where this account does not deviate from Fish's insights. Fish is descriptively correct to the extent that most people most of the time exist in a simple state of transparency. He goes astray only when he totalizes and insists that one can never achieve reflective self-consciousness and escape the universalizing tendency of one's own convictions. Similarly, he is correct in my view when he argues that utopian efforts such as the Habermasian project of developing an "ideal speech situation" are impossible because there can be no transcendent position "outside" the prevailing realm of purposes. ${ }^{244}$ Where Fish goes wrong is the moment he totalizes and argues that there can be no self-consciousness at all, and that self-consciousness could not in any event enable change.

What turns on this disagreement? Why do I claim that "the other third is the part that really matters"? The appropriate testing ground for this disagreement is the practice of judging, which is after all the subject of the Dennis Martinez essay.

What does Fish's judge look like? " $[\mathrm{A}] \mathrm{n}$ experienced-that is practiced-judge is working simply by being what practice has enabled him to be. ..."245 Thus, Fish's judge is the kind of person who is embedded within the practice of judging and "it is within it that he sees."246 We have seen what this means: "To think within a practice is to have one's very perception and sense of possible and appropriate action issue 'naturally'-without further reflection-from one's position as a deeply situated agent."247

Thus, Fish argues that we needn't worry about judges because their "practice is already principled, since at every moment it is ordered by an understanding of what it is a practice of (the law, basketball) ...."248 Indeed, Fish's judges always and already know how to "do" judging because: "To be a judge . . . is not to be able to consult the rules (or, alternatively, to be able to disregard them) but to have become an extension of the know-how that gives the rules (if there happen to be any) the meaning they will immediately and obviously have."249 In fact, Fish goes so far as to assert that

244. Critical Self-Consciousness, in Doing What Comes Naturally, supra note 2, at 450-56.

245. Dennis Martinez, in Dolng What Comes Naturally, supra note 2, at 388.

246. Id. at 382 .

247. Id. at $386-87$ (emphasis in original).

248. Fish $v$. Fiss, in Doing What Comes Naturally, supra note 2, at 125 (emphasis in original).

249. Id. at 128. In a footnote, Fish provides the caveat that he does "not mean to preclude self-conscious deliberation on the part of situated agents; it is just that such deliberations always occur within ways of thinking that are themselves the ground of consciousness, not its objects." Dennis Martinez, in Doing What Comes Naturally, supra note 2, at 565 n.19. It is hard to know what he means by this: It is precisely the space between the strong assertion in his text and the caveat in the footnote in which the debate lies. What is the value of "selfconscious deliberation on the part of situated agents" according to Fish if it is incapable of examining the ground of its consciousness? And if there is no value to such self-consciousness, as he claims, then why does he bother to acknowledge it in a footnote? 
so long as the underlying rationales of the enterprise [a]re in place, so long as it [i]s understood (at a level too deep to require articulation) that judges give remedies and avoid crises, [legal] texts w[ill] be explicated so as to yield the determinate or settled result the law requires. ${ }^{250}$

As always, "don't worry, be happy."

But I am worried. Very much so. In fact, Fish's judges are precisely the kind of judges that I don't want my clients to appear before. Judges who know "immediately and obviously" what the law requires, whose sense of the "appropriate . . . issue[s] 'naturally'-without further reflection," who-like Fish-always experience their "convictions as universally, not locally, true,"251 these are judges who cannot be impartial or objective in the only way available to situated human beings (which is to say, to any of us). For as Fish has defined them, they are judges whose beliefs, convictions, and interpretive accounts are all transparent. What they see seems simply to be true. ${ }^{252}$ So what is the defendant talking about anyway? Fish's judges are the kind who will alwaysand quite falsely-experience "the feel of objective justification provided by this model of legal reasoning."253 Fish's judges recognize no contingency; they stand ready to impose their every social construction as if it issued not from their culturally situated perspective, but from Mount Sinai itself.

Now, there is every possibility that Fish is descriptively correct and that most judges are exactly as he describes them. But this is nothing to celebrate and, certainly, nothing that invites complacency. To the contrary, we may be in even worse trouble than the nihilism feared by Owen Fiss. ${ }^{254}$ If Fish is descriptively correct about judges, then to accept the second part of Fish's account of judging would be to have the worst of all possible worlds. For Fish proclaims that judging "is already principled, since at every moment it is ordered by an understanding of what it is a practice of. . . "255 But even a moment's reflection reveals that Fish's account of judging has all the vices of his interpretive community construct.

If what renders judging "principled" is only the fact that we can recognize it as judging and not philosophizing, then we have constraint that is no constraint at all. It is still the "practice of judging" whether

250. Id. at 138 (emphasis added).

251. Critical Self-Consciousness, in Dorng What Comes Naturally, supra note 2, at 467 (quoted in full at text accompanying note 53 supra).

252. See Roy SCHAFER, AsPECtS OF INTERNALIZATION 109 (1968) ("When the subject suspends his reflective self representations, he disappears as thinker and experiences his thoughts as though they were concrete realities.").

253. Winter, supra note 2 , at 2267 (describing the socially constructed nature of legal reasoning according to internalized models or "situation-sense").

254. See Owen M. Fiss, Objectivity and Interpretation, 34 Stan. L. Rev. 739, 740-41, 762-63 (1982). This is the article to which Fish is responding in Fish v. Fiss, in DoIng What Comes NATURALLY, supra note 2, at 120.

255. Id. at 125 (emphasis in original). 
the judge says "guilty" or "not guilty." If the law is always subject to interpretation-and every rule is subject to different interpretations, as Fish has repeatedly argued ${ }^{256}$ - then judges will be "constrained" by a role that allows them to decide any given case in innumerable ways. "Constraint" turns out to be nothing more than the chimera that the "judge always knows in general what to do (avoid crises, give a remedy), although his ways of doing it will vary with the nature of the case, with the forces (political, social, legislative) pressing for this or that decision, with the (interpreted) history of previous decisions."257 This is hardly enough to "yield the determinate or settled result the law requires."258 Indeed, it is hardly anything useful at all.

Once again, it is important to note where I agree with Fish. I am not arguing that the judge is radically free. As I have argued elsewhere, "the judge, no less than others, is enmeshed in and dependent upon the structures of social meaning that make communication possible." 259 But the stock of social practices will be sufficiently rich, and the power of imaginative elaboration sufficiently fecund, that the judge's decisions will be constrained but not determined. Thus, although there are cultural constraints on judges, those constraints are partial rather than total, local rather than universal. Because the judge is not situated in a totalizing container with hard edges, the social and cultural constraints that do exist are not nearly sufficient for the kind of complacency Fish recommends.

As I have argued elsewhere, the relative indeterminacy of legal doctrine is complex, yielding patterns of both stability and flexibility. ${ }^{260}$ In my view, the project of legal theory is to explore these processes, map these patterns, and unearth the underlying cultural models that animate legal doctrine and structure judicial decisionmaking. This is not the endeavor of objectivist theory - to guide practice with a formula or rule-but rather a project of situated self-consciousness.

In his typically totalizing way, Fish compounds the two approaches. Thus, when Roberto Unger observes that "every branch of doctrine must rely tacitly if not explicitly upon some picture of the forms of human association that are right and realistic in the areas of social life with which it deals," 261 Fish misreads this as a claim for theory of the

256. See, e.g., Don't Know Much About the Middle Ages, in Doing What Comes Naturally, supra note 2, at 295, 302; Working on the Chain Gang, in Doing What Comes Naturally, supra note 2, at 89-90; Wrong Again, in Doing What Comes Naturally, supra note 2, at 106-10.

257. Fish v. Fiss, in DoIng What Comes Naturally, supra note 2, at 137 (emphasis added).

258. Id. at 138 .

259. Winter, supra note 2 , at 2255-56.

260. Winter, supra note 26 , at $1182-93$ (demonstrating and describing the structured indeterminacy and complex, socially contingent, radial models of legal doctrine). I have called this mixture of structure and indeterminacy "nondeterminacy," providing extensive illustrations. Winter, supra note 2, at 2244-55.

261. Roberto Mangabeira Unger, The Critical Legal Studies Movement, 96 Harv. L. Rev. $\mathbf{5 6 1 , 5 7 0}$ (1983). 
sort that stands "above" practice. ${ }^{262}$ But Unger is right; the relative determinacies of legal doctrine are a product of underlying, socially constructed visions of the world. In fact, Roberto Unger is saying no more than Stanley Fish acknowledges in his better moments: that all interpretation is relative to a "vision" or set of assumptions about purposes and goals that form the "background conditions of intelligibility."263 The project of legal theory (with a small-t) is to open these "guiding visions" to our view, to render them translucent, so we are not condemned to the mistake of thinking that our beliefs are simply "true."

I don't want my judges to "do what comes naturally," or my law teachers either. I want my judges to be good judges and my law teachers to be good law teachers-which is to say that I want both to do the really hard work of understanding what we do, how we do it, and what it does to those upon whom we "practice."264 I especially want my judges to be the kind of listeners who are self-conscious about their assumptions and the consequent shape of the interpretations they place on the cases and claims before them.

[T] he moral is ... to notice what one is doing, and in particular to notice what people are saying. For it might turn out, it very often does turn out, that people are trying to tell you that they are suffering. Just insofar as one is preoccupied. . ., people are likely to suffer still more. ${ }^{265}$

\section{Everything Matters, Always}

I said at the start that Fish is about two-thirds correct. He has done a real service in refocusing the debate away from the polar alternatives of objectivist fixity or subjectivist license, the either/or, all-or-nothing trap implicit in the traditional subject/object dichotomy. ${ }^{266}$ But there is the small problem of the other third. It simply is not enough to say that we are all constituted by social choices and constrained by already constructed alternatives. For, as soon as there are two such alternatives (and Fish frequently acknowledges that there are), ${ }^{267}$ we are faced with the irreducible problem of choice. How does the situated subject

262. Dennis Martinez, in Dorng What Comes Naturally, supra note 2, at 379-80.

263. Don't Know Much About the Middle Ages, in Doing What Comes Naturally, supra note 2, at 295; Consequences, in DoIng What Comes Naturaldy, supra note 2, at 317 (" $[\mathrm{t}] \mathrm{he}$ rule-of-thumb reader begins with a knowledge of the outcome he desires, and it is within such knowledge that the rule assumes a shape, becomes readable").

264. An excellent example of this sort of scholarship, which identifies the five unstated assumptions that animate judicial decisionmaking in cases involving difference, is Martha Minow, The Supreme Court 1986 Term-Foreword: Justice Engendered, 101 Harv. L. REv. 10, 34-57 (1987).

265. RichaRd RORTY, CONTINGENCY, IRONY, AND SOLIDARTYY 164 (1988).

266. For further discussion of these limitations, and of a potential way out, see Winter, supra note 26 , at $1107-13,1127-34$.

267. See, e.g., Don't Know Much About the Middle Ages, in Doing What Comes Naturally, supra note 2, at 295; Wrong Again, in Dorng What Comes NATURALLY, supra note 2, at 109-10. 
choose? What social forces press the subject in one direction or the other? These are the questions-what occurs within the space of social and imaginative construction-that are worth considering, that need to be considered.

I have tried to show, moreover, that we need to reconsider some of the previously unexamined assumptions of the antifoundationalist position. For, as it is currently understood, it threatens either the nihilism so many fear or the false complacency that Fish's arguments suggest. This should be unacceptable to the legal profession because, in Robert Cover's haunting admonition: "Legal interpretation takes place in a field of pain and death."268 It should be equally unacceptable to the academic community because, as Stanley Fish so ably points out, the academy is no less characterized by the uses of power. ${ }^{269}$ Where there is power, there is also abuse. Everything matters, always.

Bromides like "interpretive communities," "practice," and the like mask this predicament with a false complacency. They obscure responsibility and make morality impossible.

Morality, in this context, is most easily grasped as the antithesis of social and material reality, as the human response to the awareness of choice, the awareness that our actions might make a difference. ... Morality ... is ... the awareness that one possesses power and that its exercise will affect other humans. ${ }^{270}$

When the needs, hopes, fears, and physical well-being of other humans are at stake, the Martinez refrain-"What else could I do? What else could I say?"- -sounds like nothing so much as abdication.

This creates a real problem, whether you are an antifoundationalist like Fish or a nonobjectivist like me. "Morality which is no particular society's morality is to be found nowhere."271 I know of no transcendent morality that we can consult and invoke to mediate or adjudicate moral claims. "We start, on any occasion, with some old version or world that we have on hand and that we are stuck with until we have the determination and skill to remake it into a new one."272 The tools with

268. Robert M. Cover, Violence and the Word, 95 YALE L.J. 1601, 1601 (1986). Note that this is a use of the container schema that has the bite of reality to it.

269. Fish v. Fiss, in Doing What Comes Naturally, supra note 2, at 135-36.

270. J.G. Deutsch, Teaching Corporate Law: A Socratic Investigation of Law and Bureaucracy, 97 YALE L.J. 96, 108 (1987). Deutsch characterizes this approach to morality as "something purely individual." Id. What I understand him to mean is that morality is not simply the code of acceptable behavior defined by a social group, but rather the acceptance of responsibility for one's actions in the world. In my view, the characterization of morality as "purely" individual is somewhat misleading because the concept of morality that Deutsch explicates is distinguished by its recognition of the interactive and socially interdependent nature of human action. Indeed, with Fish, I go further and reject the notion of the "purely individual" because the modern concept of an individual is largely a social construction. See Winter, supra note 2, at 2254 n.99 (discussing cross-cultural differences in construction of "self"). 1984).

271. Alasdair Macintyre, Postscript to the Second Edition, in After Virtue 265-66 (2d ed.

272. N. Goodman, supra note 101 , at 97. 
which we start must always be what we take as the best of the moral traditions of our culture. ${ }^{273}$ But it is never the tools that do the job; morality, like art, is the work of the imagination. Morality requires selfreflection; it calls for an exercise of imagination that sees past the presumed naturalness of the current forms of social life, first to imagine and then to create the possibilities of change. ${ }^{274}$

Most of us were brought up to believe that we spoke prose-that poetry, creativity, metaphor and the like were special gifts. One of the truly wonderful aspects of the recent developments in cognitive theory is the democratization of imagination, the discovery of "that part of the ability of every language-user which is poetic."275 There is something glorious about the irrepressibly imaginative, creative, and fecund quality of human rationality. Indeed, it is hard to imagine how we could have survived as a species without it as an adaptive mechanism. The need for it today is no less acute. So enough of these totalizing constructs; too much closure can only get in the way. We need always to be conscious that everything matters, and that we will always and already be better off if we pool our imaginative resources as we construct our insights from whatever materials come to hand.

And so, we end with baseball-but not as we began. Dennis Martinez is now with the Montreal Expos. He is doing much better than when he last appeared in the law reviews. ${ }^{276} \mathrm{He}$ won fifteen games in the 1988 season, and his record for 1989 was sixteen and seven. ${ }^{277}$ Maybe he stopped trying to do Wittgenstein on the mound, maybe he started getting more self-reflective, or maybe he saw Bull Durham. You know, maybe he would be willing to commend to Fish the advice Crash gave to Nuke: "Hey. Relax. All right? Don't try to strike everybody out. Strikeouts are boring. Besides they're fascist. Throw some groundballs. It's more democratic."

273. Cf. Ronald Dworkin, Law's Empire 225-28 (1986). And, on this very point, it seems that Fish would agree:

One could call it business as usual so long as "business as usual" is understood to include looking around (with institution-informed eyes) to see conditions (institutionally established) that are unjust or merely inefficient (with justice and inefficiency institutionally defined) and proposing remedies and changes that will improve the situation.

Anti-Professionalism, in Doing What Comes Naturally, supra note 2, at 243.

274. This is much more difficult than typically assumed, as I have argued elsewhere. See Winter, supra note 2, at 2244-45 (arguing that the grounding of cognition in already constructed social experience makes dramatic social transformation a formidable though not impossible task). For further development of this point, see Steven $\mathrm{L}$. Winter, Indelerminacy and Incommensurability in Constitutional Law (1990) (forthcoming) (discussing and relating to law Merleau-Ponty's concepts of "sedimentation" and "adversity").

275. A. MACINTYRE, supra note 133 , at 382.

276. See Dennis Martinez, in Doing What Comes Naturaldy, supra note 2, at 372 ("Martinez is a pitcher who is unlikely ever to make it into the baseball Hall of Fame"); Schlag, supra note 24, at 58 (Martinez, Weaver, and the Orioles lost the game referred to by Fish).

277. Baseball: Humble Expos, N.Y. Times, July 24, 1989, at 31, col. 2; Major League Averages, N.Y. Times, October 1, 1989, at 28, col. 5. 
